\title{
Nanotechnology: A Promising Approach for Delivery of Neuroprotective Drugs
}

\author{
Saba Naqvi*, Archna Panghal and S. J. S. Flora* \\ Department of Pharmacology \& Toxicology, National Institute of Pharmaceutical Education and Research, Raebareli, India
}

\section{OPEN ACCESS}

Edited by:

Syed Shadab Raza

ERA's Lucknow Medical College, India

Reviewed by:

Sivakumar Vijayaraghavalu, Cleveland Foundation, United States

Mohd Nazam Ansari,

Prince Sattam Bin Abdulaziz

University, Saudi Arabia

Mohammed Samim,

Jamia Hamdard University, India

*Correspondence:

Saba Naqvi

writetosaba@yahoo.com

S. J. S. Flora

sjsflora@gmail.com

Specialty section:

This article was submitted to

Neural Technology,

a section of the journal

Frontiers in Neuroscience

Received: 08 October 2019

Accepted: 20 April 2020

Published: 09 June 2020

Citation:

Naqvi S, Panghal $A$ and Flora SJS (2020) Nanotechnology: A Promising

Approach for Delivery

of Neuroprotective Drugs.

Front. Neurosci. 14:494.

doi: 10.3389/fnins.2020.00494
Central nervous system (CNS) disorders especially neurodegenerative disorders are the major challenge for public health and demand the great attention of researchers to protect people against them. In past few decades, different treatment strategies have been adopted, but their therapeutic efficacy are not enough and have only shown partial mitigation of symptoms. Blood-brain barrier (BBB) and blood-cerebrospinal fluid barrier (BSCFB) guard the CNS from harmful substances and pose as the major challenges in delivering drugs into CNS for treatment of CNS complications such as Alzheimer's disease (AD), Parkinson's disease (PD), Huntington's disease (HD), stroke, epilepsy, brain tumors, multiple sclerosis (MS), and encephalitis, etc. Nanotechnology has come out as an exciting and promising new platform of treating neurological disorders and has shown great potential to overcome problems related to the conventional treatment approaches. Molecules can be nanoengineered to carry out multiple specific functions such as to cross the BBB, target specific cell or signaling pathway, respond to endogenous stimuli, and act as a vehicle for gene delivery, support nerve regeneration and cell survival. In present review, the role of nanocarrier systems such as liposomes, micelles, solid lipid nanoparticles (SLNPS), dendrimers, and nanoemulsions for delivery of various neurotherapeutic agents has been discussed, besides this, their mechanism of action, and nanoformulation of different neuroprotective agents like curcumin, edaravone, nerve growth factors in CNS disorders like Alzheimer's, Parkinsonism, epilepsy, stroke, and brain tumors has been reviewed.

Keywords: nanotechnology, nanoformulations, targeted delivery, blood-brain barrier, neurological disorders, neuroprotection

\section{INTRODUCTION}

Central nervous system (CNS) disease and disorders are posing great challenge for mankind and is the fastest growing area appealing for the attention of researchers. Today, neurological disorders are among the highest reasons for causing death and disability in the world. The contribution of CNS disorders to the global burden of disease is increasing and globally, in 2016, neurological disorders were the leading cause of disability-adjusted life-years (DALYs) [276 million (95\% UI 247-308)] and 
second leading cause of deaths [9.0 million (8.8-9.4)] (Feigin et al., 2019). To date, the diagnosis and treatment of the neurological disorders such as Alzheimer's disease (AD), Parkinson's disease (PD), Huntington's disease (HD), head trauma, brain tumor, and epilepsy are still a challenging task (Barchet and Amiji, 2009). A wide spectrum of potential drugs has been investigated to treat several neurological disorders but their therapeutic success is still limited due to range of challenges. One of the most common challenge is the difficulty in delivering agents such as drugs, nucleic acids, proteins, imaging agents and other macromolecules to the CNS across the peripheral barriers, namely blood-brain barrier (BBB) and blood-cerebrospinal fluid barrier (BCSFB), particularly the BBB (Pathan et al., 2009; Wong et al., 2012). Figure 1 showing different smuggling pathways of drug through which it may enter into the brain.

The current neurotherapeutics are associated with two major limitations i.e., before entering into brain cells they are pose to limited entry via $\mathrm{BBB}$ as insufficient entry in brain as well as of limited access to immune cells to brain (Misra et al., 2003; Nagpal et al., 2013). Most of the drugs used in neural diseases are lipophilic in nature having molecular weight greater 400-500 $\mathrm{Da}$ and not able to cross the BBB in pharmacologically significant quantity (Fischer et al., 1998) hence do not pass in initial screening whereas small lipophilic molecules (alcohol and steroid hormones) penetrate via transcellular mechanism. However, the presence of different transporters on endothelial cells which are highly selective in nature also limits the drugs entry. Also the presence of Tight junctions (TJ) in endothelial membranes creates high transendothelial electrical resistance (TEER) $\left(>1000 \mathrm{~W} \mathrm{~cm}^{2}\right)$ in cerebral microcapillaries (Gloor et al., 2001). The endothelial cells of $\mathrm{BBB}$ restrict the passage or entry of endogenic/foreign materials. ATP-binding cassette (ABC) transporters present over the endothelial cells and restrict the therapeutic drug entry also along with neurotoxic agents/metabolites/hormones/mediators. These transporters are membrane proteins require ATP to transport materials through cell membranes. Multiple drug resistance protein 1 (MDR1) or ATP-binding cassette sub-family B member 1 (ABCB1), which is well known as permeability glycoprotein (P-gp), multiple resistance protein 4 (MRP4) or ATP-binding cassette sub-family $\mathrm{C}$ member 4 (ABCC4), and breast cancer resistance protein (BCRP) or ATP-binding cassette sub-family $G$ member2 (ABCG2) are members of this family (Alyautdin et al., 2014). The BBB also maintains the ionic homeostasis at synapses, where it regulates the entry of potassium ions $\left(\mathrm{k}^{+}\right)$, calcium $\left(\mathrm{Ca}^{2+}\right)$, sodium $\left(\mathrm{Na}^{+}\right)$and maintains minimum optic concentrations.

The BBB is made up of monolayer of polarized endothelial cells connected by complex tight junctions, and its functionality is controlled by cells such as astrocytes, neurons, and pericytes. The complexity of $\mathrm{BBB}$, the existence of high levels of efflux transport proteins including P-glycoproteins (P-gp) and Multidrug Resistant Protein-1 (MRP-1), and the expression of metabolic enzymes limits the entry of drug inside the brain (Tajes et al., 2014).

Recently, efforts such as alterations in the permeability efficiency of the $\mathrm{BBB}$, carrier and receptor-mediated drug delivery, have been adopted to overcome the obstacles faced during successful treatment, even though the impact of most of these strategies has been found not much effective. Lipidization of a molecule with a lipid layer, disruption of BBB by means of ultrasound technique or radiation therapy and use of nanomaterials are some methods to help drug delivery across BBB (Poovaiah et al., 2018). Among these methods, nanotechnology-based drug delivery is a quite new as compare to conventional methods and promising approach in the field of neuro disorders, as nanocarriers have been proved efficacious in effectively traversing the $\mathrm{BBB}$ or BCSFB and thus effectively delivering drugs within the CNS to the target site (Silva, 2005; Jain, 2007; Wong et al., 2012; Li et al., 2017). The Table 1 describes the few of the FDA approved nanodrugs available clinically for different indications (Ventola, 2017). The average size of human cells is $10-20 \mu \mathrm{m}$, where as the minimal diameter of blood capillaries are 6-9 $\mu \mathrm{m}$, due to their nano size ranges nanomaterials get easily transported and internalizes by brain capillary endothelial cells via endocytosis and transcytosis mechanism of transport (Vilella et al., 2014). Different nanocarriers of particle size between 1 and $100 \mathrm{~nm}$ have been emerged by the development of nanotechnology, among which polymeric nanoparticles (PNPs), solid lipid nanoparticles (SLNPs), liposomes, and micelles made their debut as nanocarriers for treatment of various neurological disorders. But, nowadays, newer and more advanced nanosystems, such as dendrimers, nanoemulsions (Bonferoni et al., 2019), nanogels, nanosuspensions, and nanotubes, etc., which have shown great potential than previous delivery systems, developed by the nanotechnological approach (Rajadhyaksha et al., 2011; Wong et al., 2012; Ozkizilcik et al., 2017; Alexander et al., 2019). The selection of an appropriate nanocarrier system is a prerequisite for effective delivery of drug to CNS across BBB. The size, surface area, surface charge and morphology of nanocarriers have a remarkable impact on their passage across CNS barriers. The nanocarriers used in CNS drug delivery should have optimum size, surface area, surface charge and should be biodegradable, non-toxic, biocompatible, cost-effective and site-specific (Chakraborty et al., 2017). Various nanodrug system such as polymers, micelles, liposomes, dendrimers, nanocrystals, SLNPs have been used to improve efficacy, safety physiological properties pharmacokinetics, and pharmacodynamics of drugs (Figure 2) (Shegokar and Müller, 2010; Chan and Kwok, 2011; Gao et al., 2012; Thomas et al., 2013). The major targets in the development of nanomedicine are:

(a) Safety, and high efficacy.

(b) Drug targeting to specific sites to reduce off target toxicity.

(c) Improved pharmacokinetic behavior by sustained drug release with wide safety margin.

Although it is quite difficult to say which nanoparticulate drug delivery system is having more potential and safe among listed nanocarriers such as polymers, micelles, liposomes, dendrimers, nanocrystals, SLNPs, the size, shape, composition, surface charge, 


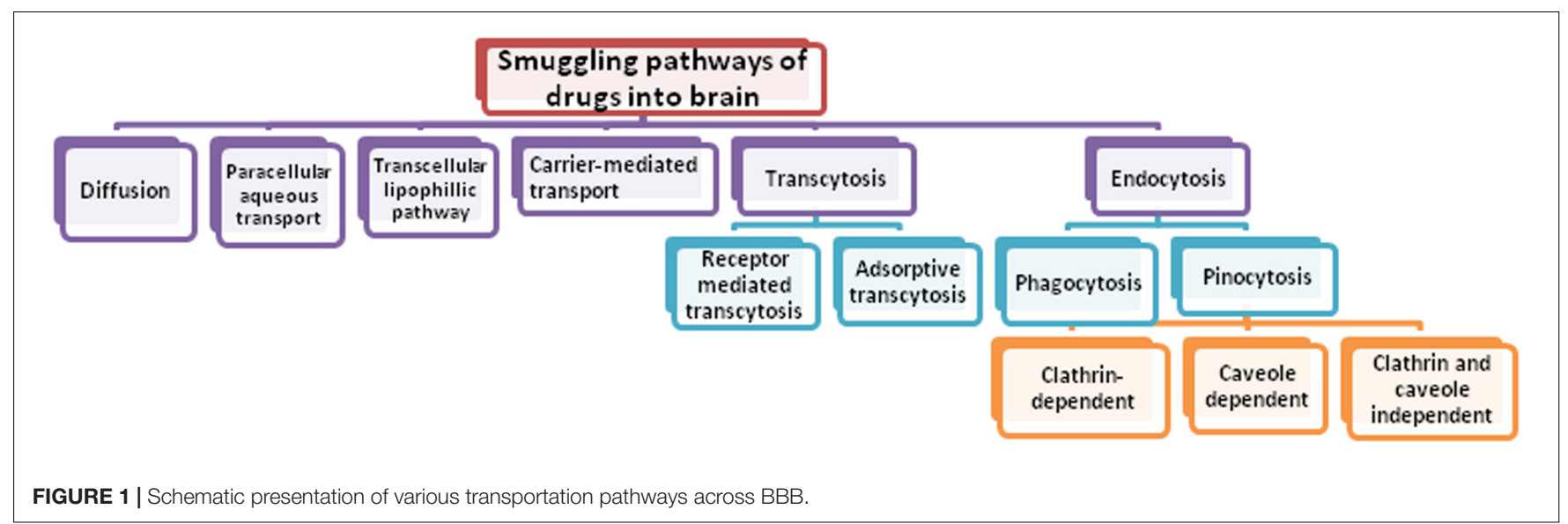

monomers molar ratio, solubility of drug, their physiochemical properties and further their release in different acidic and basic environment inside cells, plays very important role in pharmacokinetics of each type of nanocarriers. Tables 2, 3 describes pharmacokinetics of each type of nanocarriers and their biocompatibility, respectively.

Targeted delivery of the drug is a promising approach to minimize the side effects of a therapeutic agent. Nanocarrier based brain targeted delivery can be accomplished via receptormediated, transporter-mediated and pharmacological disruption of $\mathrm{BBB}$. Decorating the delivery system with $\mathrm{BBB}$ receptor ligands, coupling antibodies, peptides or aptamers with $\mathrm{BBB}$ receptor ligand delivery system, and transporter ligands coupled micelle delivery are some of the approaches for nanocarriers based brain targeting (Guo et al., 2012; Gao et al., 2013). In the current review, we provide an overview of different nanoformulations of neuroprotective agents, with particular emphasis on their usefulness in different neurological diseases and the opportunities for future research.

\section{NANO APPROACHES TOWARD CNS DRUG DELIVERY}

Nanotechnology is an innovative, promising and cutting edge approach for delivering neurotherapeutics across BBB. In the last few decades, nanomedicines have shown great potential toward CNS drug delivery owing to its nanosize range, their unique physic-chemical properties and ability to exploit surface engineered biocompatible and biodegradable nanomaterials (Kaur et al., 2008). Nanotechnology-based approaches for site-specific delivery of therapeutics and other compounds across the BBB may potentially be engineered to carry out particular functions as needed. The drug, the pharmacologically active component to be delivered, itself constitutes one part of the nanoengineered complex while remaining complex is intended to accomplish other key functions such as encapsulating the active drug protection against enzymatic degradation, drug release at specific $\mathrm{pH}$, ability to cross the $\mathrm{BBB}$, and targeting specific brain cells (Silva, 2008). A wide range of pharmaceutical nanocarriers including liposomes, PNPs, SLNs, micelles, dendrimers, and some others have been developed (Rajadhyaksha et al., 2011; Wong et al., 2012; Ozkizilcik et al., 2017).

\section{Micelles}

Micelles, the vesicles which is made up of amphiphilic surfactants (non-polymeric micelles) or amphiphillic copolymers (polymeric micelles) have recently fascinated the researchers as a novel drug carrier system to the CNS (Aliabadi and Lavasanifar, 2006; Torchilin, 2007). As compared to nonpolymeric micelles, polymeric micelles are considered more stable having long duration of action and high biodistribution (Ozkizilcik et al., 2017). They have a core-shell structural design with size ranging from 10 to $100 \mathrm{~nm}$ consisting outer hydrophilic environment mostly made up of polyethylene glycol (PEG) and inner hydrophobic core synthesized by means of molecules such as polycaprolactone, polypropylene glycols, phospholipids, and fatty acids, thus they allow loading of hydrophobic drugs (Torchilin, 2007). The external hydrophilic shell provides stability to micelles in an aqueous environment and prolongs their circulation time in bloodstream, thus protecting it from reticulo-endothelial system (RES) and further facilitate their accumulation in specific region having leaky vasculature (Park et al., 2008). The class of pluronic (also known as Poloxamers) block copolymers is of particular interest as they have an ability to hinder drug efflux transporters, for instance, inhibition of P-gp efflux transporters widely expressed on $\mathrm{BBB}$ and enhance drug shipment to the CNS (Batrakova and Kabanov, 2008). Moreover, it was demonstrated that they facilitate the brain delivery of low molecular mass drugs incorporated into them by escalating the drug solubility and stability in plasma.

Number of attempts has been made to transform the micelles in such a way that enhanced concentration of loaded drug can cross on another side of BBB easily. One such modification is attaching either polyclonal antibodies against brain-specific antigen, $\alpha 2$-glycoprotein, or insulin to target the receptor at the luminal side of BBB. In mice, the intravenous administration of these modified micelles after loading with a fluorescent dye or 
TABLE 1 | Clinically available FDA-approved nanoformulated drugs (Sainz et al., 2015; Bobo et al., 2016; Caster et al., 2017; Centerwatch, 2017; Flexion Therapeutics Inc, 2017; Food and Drug Administration, 2017; Ventola, 2017).

\begin{tabular}{|c|c|c|c|}
\hline Generic name & Trade name (Manufacturer) & Disease & Advantages \\
\hline \multicolumn{4}{|l|}{ Polymer NPs } \\
\hline Copaxone (Teva) & Glatimer acetate & Multiple sclerosis & Controlled clearance \\
\hline Eligard (Tolmar) & Leuprolide acetate and polymer & Prostate cancer & $\begin{array}{l}\text { Extended circulation time, controlled payload } \\
\text { delivery }\end{array}$ \\
\hline Adynovate (Shire) & $\begin{array}{l}\text { Antihemophilic factor } \\
\text { (recombinant), pegylated }\end{array}$ & Hemophilia & Better protein stability, longer half-life \\
\hline Cimzia (UCB) & Certolizumab pegol & $\begin{array}{l}\text { Crohn's disease, rheumatoid arthritis, } \\
\text { psoriatic arthritis, and ankylosing } \\
\text { spondylitis }\end{array}$ & $\begin{array}{l}\text { Extended circulation time, greater stability in } \\
\text { vivo }\end{array}$ \\
\hline Mircera (Vifor) & $\begin{array}{l}\text { Methoxy polyethylene } \\
\text { glycol-epoetin beta }\end{array}$ & Anemia associated with CKD & High aptamer stability \\
\hline Neulasta (Amgen) & Pegfilgrastim & Chemotherapy-induced neutropenia & High protein stability \\
\hline Krystexxa (Horizon) & Pegloticase & Chronic gout & High protein stability \\
\hline Macugen (Bausch and Lomb) & Pegaptinib & Neovascular AMD & High aptamer stability \\
\hline Adagen (Leadiant Biosciences) & Pegademase bovine & SCID & $\begin{array}{l}\text { Longer circulation time, decreased } \\
\text { immunogenicity }\end{array}$ \\
\hline Oncaspar (Baxalta United States) & Pegaspargase & ALL & High protein stability \\
\hline Pegasys (Genentech) & Pegylated IFN alpha-2a & Hepatitis B, hepatitis C & High protein stability \\
\hline Peglntron (Merck) & Pegylated IFN alpha-2b & Hepatitis C & Greater protein stability \\
\hline Somavert (Pfizer) & Pegvisomant & Acromegaly & High protein stability \\
\hline Zilretta (Flexion Therapeutics) & $\begin{array}{l}\text { Triamcinolone acetonide ER } \\
\text { injectable suspension }\end{array}$ & Osteoarthritis knee pain & Extended release \\
\hline Plegridy (Biogen) & Pegylated IFN beta-1a & Multiple sclerosis & High protein stability \\
\hline Rebinyn (Novo Nordisk) & $\begin{array}{l}\text { Coagulation factor IX (recombinant), } \\
\text { glycopegylated }\end{array}$ & Hemophilia B & $\begin{array}{l}\text { Prolonged half-life, higher drug levels } \\
\text { between infusions }\end{array}$ \\
\hline $\begin{array}{l}\text { Renvela (Genzyme); and Renagel } \\
\text { (Genzyme) }\end{array}$ & $\begin{array}{l}\text { Sevelamer carbonate; and } \\
\text { Sevelamer } \mathrm{HCl}\end{array}$ & CKD & $\begin{array}{l}\text { Prolonged circulation time and therapeutic } \\
\text { delivery }\end{array}$ \\
\hline \multicolumn{4}{|l|}{ Liposome NPs } \\
\hline DepoDur (Pacira Pharmaceuticals) & Liposomal morphine sulfate & Postoperative analgesia & Prolonged release \\
\hline Marqibo (Spectrum Pharmaceuticals) & Liposomal vincristine & ALL & $\begin{array}{l}\text { High delivery to tumor site, decreased } \\
\text { systemic toxicity }\end{array}$ \\
\hline Onivyde (Ipsen Biopharmaceuticals) & Liposomal irinotecan & Pancreatic cancer & $\begin{array}{l}\text { High delivery to tumor site, decreased } \\
\text { systemic toxicity }\end{array}$ \\
\hline Curosurf (Chiesi United States) & Poractant alfa & Respiratory distress syndrome & $\begin{array}{l}\text { High delivery with low volume, decreased } \\
\text { toxicity }\end{array}$ \\
\hline Doxil (Janssen) & Doxorubicin $\mathrm{HCl}$ liposome injection & $\begin{array}{l}\text { Karposi's sarcoma, ovarian cancer, } \\
\text { multiple myeloma }\end{array}$ & $\begin{array}{l}\text { High delivery to disease site, less systemic } \\
\text { toxicity }\end{array}$ \\
\hline Abelcet (Sigma-Tau) & Liposomal amphotericin B & Lipid complex fungal infections & Reduced toxicity \\
\hline AmBlsome (Gilead Sciences) B & Liposomal amphotericin & Fungal/protozoal infections & Reduced nephrotoxicity \\
\hline Visudyne (Bausch and Lomb) & Liposomal verteporfin & Wet AMD, ocular histoplasmosis, myopia & Improved delivery to site of diseased vessels \\
\hline Vyxeos (Jazz Pharmaceuticals) & $\begin{array}{l}\text { Liposomal daunorubicin and } \\
\text { cytarabine }\end{array}$ & $\begin{array}{l}\text { AML, AML with myelody splasiarelated } \\
\text { changes }\end{array}$ & $\begin{array}{l}\text { Enhanced efficacy through synergistic } \\
\text { delivery of }\end{array}$ \\
\hline \multicolumn{4}{|l|}{ Micelle NPs } \\
\hline Estrasorb (Novavax) & Micellar estradiol & Vasomotor symptoms in menopause & Controlled delivery \\
\hline \multicolumn{4}{|l|}{ Inorganic NPs } \\
\hline Ferrlecit (Sanofi-Aventis) & $\begin{array}{l}\text { Sodium ferric gluconate complex in } \\
\text { sucrose injection }\end{array}$ & Iron deficiency in CKD & Increased dose \\
\hline Infed (Actavis Pharma) & Iron dextran & Iron deficiency in CKD & Increased dose \\
\hline Venofer (American Regent) & Iron sucrose & Iron deficiency in CKD & Increased dose \\
\hline Dexferrum (American Regent) & Iron dextran & Iron deficiency in CKD & Increased dose \\
\hline Feraheme (AMAG Pharmaceuticals) & Ferumoxytol & Iron deficiency in CKD & $\begin{array}{l}\text { Prolonged, steady release with less frequent } \\
\text { dosing }\end{array}$ \\
\hline
\end{tabular}


TABLE 1 | Continued

\begin{tabular}{|c|c|c|c|}
\hline Generic name & Trade name (Manufacturer) & Disease & Advantages \\
\hline \multicolumn{4}{|l|}{ Protein NPs } \\
\hline Ontak (Eisai) & Denileukin diftitox & Cutaneous T-cell lymphoma & $\begin{array}{l}\text { Targeted T-cell specificity, lysosomal } \\
\text { escape }\end{array}$ \\
\hline Abraxane (Celgene) & Albumin-bound paclitaxel & Breast cancer, NSCLC, pancreatic cancer & $\begin{array}{l}\text { Greater solubility, increased delivery to } \\
\text { tumor }\end{array}$ \\
\hline \multicolumn{4}{|l|}{ Nanocrystal NPs } \\
\hline Tricor (AbbVie) & Fenofibrate & Hyperlipidemia & $\begin{array}{l}\text { Increased bioavailability simplifies } \\
\text { administration }\end{array}$ \\
\hline Vitoss (Stryker) & Calcium phosphate & Bone substitute & Mimics bone structure \\
\hline Zanaflex (Acorda) & Tizanidine $\mathrm{HCl}$ & Muscle relaxant & High drug loading and bioavailability \\
\hline Avinza (Pfizer) & Morphine sulfate & Psychostimulant & High drug loading and bioavailability, EF \\
\hline EquivaBone (Zimmer Biomet) & Hydroxyapatite & Bone substitute & Mimics bone structure \\
\hline Emend (Merck) & Aprepitant & Antiemetic & Absorption and bioavailability increases \\
\hline Focalin (Novartis) & Dexamethylphenidate $\mathrm{HCl}$ & Psychostimulant & Higher drug loading and bioavailability \\
\hline Megace ES (Par Pharmaceuticals) & Megestrol acetate & Antianorexic & Lower dosing \\
\hline Invega Sustenna (Janssen) & Paliperidone palmitate & Schizophrenia, schizoaffective disorder & $\begin{array}{l}\text { Slow release of injectable low-solubility } \\
\text { drug }\end{array}$ \\
\hline NanOss (RTI Surgical) & Hydroxyapatite & Bone substitute & Mimics bone structure \\
\hline Ostim (Heraeus Kulzer) & Hydroxyapatite & Bone substitute & Mimics bone structure \\
\hline OsSatura (IsoTis Orthobiologics) & Hydroxyapatite & Bone substitute & Mimics bone structure \\
\hline Rapamune (Wyeth Pharmaceuticals) & Sirolimus & Immuno-suppressant & Better bioavailability \\
\hline Ritalin LA (Novartis) & Methylphenidate $\mathrm{HCl}$ & Psychostimulant & Higher drug loading and bioavailability \\
\hline Ryanodex (Eagle Pharmaceuticals) & Dantrolene sodium & Malignant hypothermia & $\begin{array}{l}\text { More rapid rate of administration at } \\
\text { higher doses }\end{array}$ \\
\hline \multicolumn{4}{|l|}{ Inorganic NPs } \\
\hline Dexferrum (American Regent) & Iron dextran & Iron deficiency in CKD & Increased dose \\
\hline Feraheme (AMAG Pharmaceuticals) & Ferumoxytol & Iron deficiency in CKD & $\begin{array}{l}\text { Prolonged, steady release with less } \\
\text { frequent dosing }\end{array}$ \\
\hline Ferrlecit (Sanofi-Aventis) & $\begin{array}{l}\text { Sodium ferric gluconate complex in } \\
\text { sucrose injection }\end{array}$ & Iron deficiency in CKD & Improved dose \\
\hline Infed (Actavis Pharma) & Iron dextran & Iron deficiency in CKD & Improved dose \\
\hline Venofer (American Regent) & Iron sucrose & Iron deficiency in CKD & Improved dose \\
\hline \multicolumn{4}{|l|}{ Protein NPs } \\
\hline Abraxane (Celgene) & Albumin-bound paclitaxel & Breast cancer, NSCLC, pancreatic cancer & $\begin{array}{l}\text { Better solubility, increased delivery to } \\
\text { tumor sites }\end{array}$ \\
\hline Ontak (Eisai) & Denileukin diftitox & Cutaneous T-cell lymphoma & $\begin{array}{l}\text { Targeted T-cell specificity, lysosomal } \\
\text { escape }\end{array}$ \\
\hline
\end{tabular}

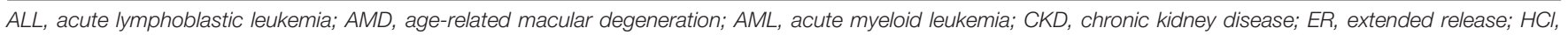
hydrochloride; IFN, interferon; NP, nanoparticle; NSCLC, non-small-cell lung cancer; SCID, severe combined immunodeficiency disease.

neuroleptic drug haloperidol, resulted in improved delivery of the fluorescent dye to the brain and drastic increase in the neuroleptic effect of haloperidol (Kabanov et al., 1989).

Another modification of the micelle system is direct conjugation of the drug molecule and targeting moiety to the amphiphilic segment. For instance, Zhang et al. (2012) studied transferrin-modified cyclo-(Arg-Gly-Asp-d-Phe-Lys)Paclitaxel conjugate-loaded micelle and demonstrated the increased uptake by the brain microvascular endothelial cells in vitro in addition to the lengthened retention in glioma tumor in vivo and no considerable toxicity was noticed. Poly lactic-glycolic acid (PLGA) nanoparticles (NPs) coated with Chitosan oleate (CS-OA) which imparts positive surface charge and Chitosan Oleate Self-Assembled Polymeric Micelles based nanosystems were prepared and compared, for their interaction with cells i.e., Caco-2 and Hela cells. micelles and PLGA NPs, loaded with lipophillic model drug i.e., resveratrol, based on release profiles, TGA analysis and the cell line interaction results PLGA-CS-OA found to be more stable compared with polymeric micelles (Miele et al., 2019).

\section{Liposomes}

Liposomes are considered as the first generation of the novel colloidal nanocarriers which were successfully proven themselves as a drug carrier system in the 70's (Bawarski et al., 2008). These are small spherical vesicles composed of the hydrophilic compartment at the center enclosed by a single or multiple phospholipid bilayers due to which they morphologically resemble with the cell membrane and are 


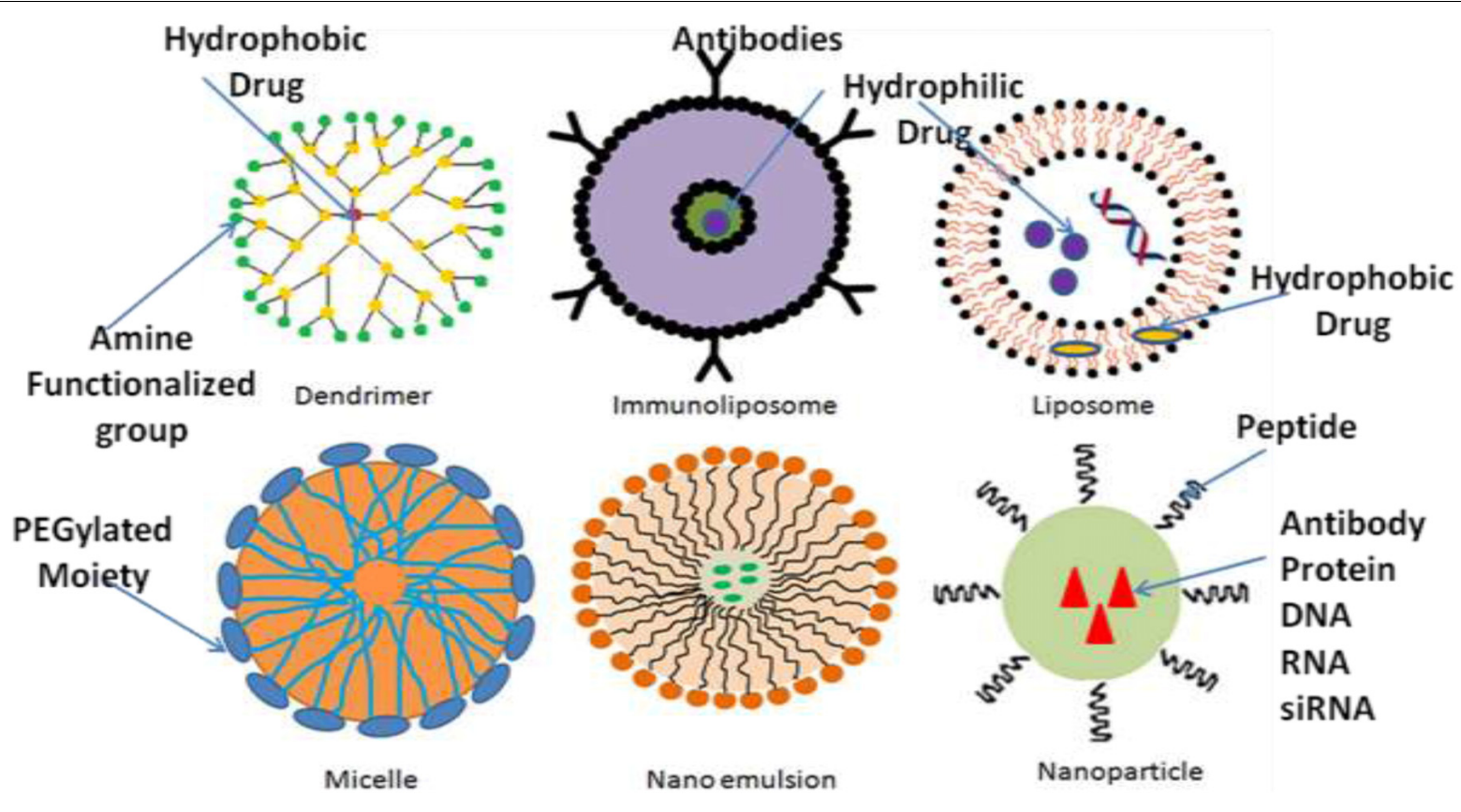

FIGURE 2 | Nanotechnology-based various CNS delivery systems.

used as a strategic approach for drug delivery,proteins and peptides (Martins et al., 2007; Wong et al., 2012; Ozkizilcik et al., 2017). They can be classified into three categories depending upon their size and number of bilayers: small unilamellar (10-50 nm), large unilamellar (50-1000 nm), and multilamellar $(20-100 \mathrm{~nm})$. These are reversible structures due to presence of non-covalent interactions such as van der walls forces and hydrogen bonding between molecules (Ramos-Cabrer and Campos, 2013).

Unmodified conventional liposomes have short circulation time in the body as they are quickly eliminated from the systemic circulation by the cells of RES and therefore various attempts have been made to develop long-circulating and targeted liposomes (Musacchio and Torchilin, 2011). Among such attempts, polyethylene glycol (PEG) coating on liposomes is a successful attempt to avoid RES recognition of nanocarrier system (Barenholz, 2012; Wong et al., 2012). Targeted delivery of PEG-modified liposomes to the brain can be facilitated by further modifications with various ligands like monoclonal antibodies (mAbs) against glial fibrillary acidic proteins, transferrin receptors (TRs) or human insulin receptors (Pardridge, 1999; Shah et al., 2013). Transferrin-conjugated liposomes have been demonstrated to preferentially deliver the payload like 5-fluorouracil to the brain facilitated by receptor-mediated endocytosis (Soni et al., 2008). Conjugation of prednisolone-loaded liposomes with mAbs that will be recognized by cell surface receptors in the targeted tissue called immunoliposomes, demonstrated further improvement in distribution of liposomes inside brain and high efficacy against experimental autoimmune encephalomyelitis (Schmidt et al., 2003). Immunoliposomes as nanocarrier systems for brain drug delivery also have some usage in gene therapy as demonstrated by TRsMAbs-targeted liposome conjugated with a plasmid for tyrosine hydroxylase in treating PD in a rat model (Zou et al., 2010). This approach has also been used for delivery of small interfering RNA (siRNA) against epithelial growth factor receptor (EGFR) and demonstrated the knockdown of EGFR expression and increased survival of mice implanted intracranially with brain tumors (Pardridge, 2007). Another approach to improve the efficiency of liposomes in crossing the barriers and increase therapeutic success is their modifications with cell penetrating peptides (CPP). For instance, specific ligand transferrin (T7) and non-specific cell penetrating peptide (TAT) conjugated doxorubicin encapsulated liposomes demonstrated high availability across BBB and specific cell targeting to the brain glioma (Zong et al., 2014). Recently nimodipine proliposomes, which form liposomal structure upon contact with water, augment the oral bioavailability of the drug (Sun et al., 2013). In another study, compounds like $\alpha$-tocopherol (Toc) and omega 3 fatty acid were loaded into liposomes with anti-Alzheimer drug tacrine for the treatment of $\mathrm{AD}$ with intranasal route (Corace et al., 2014).

\section{Polymeric Nanoparticles}

Polymeric nanoparticles are solid colloidal dispersion of biodegradable and biocompatible polymers such as poly (alkylcyanoacrylate) (PACA), polyesters such as poly (lactide) (PLA), poly (D,L-lactide-co-glycolic acid) (PLGA), and several others such as natural proteins and polysaccharides with size range 10-100 nm (Kumari et al., 2010). They consists a core of dense polymer matrix to encapsulate the lipophillic drugs and a hydrophilic corona to provide steric stability to NPs. 
TABLE 2 | Different nanoformulations with their biopharmaceutical properties.

\begin{tabular}{lll}
\hline Formulation type $\quad$ Drug name & Route of administration & $\begin{array}{l}\text { in vivo (Pharmacokinetics/ References } \\
\text { Pharmacodynamics) }\end{array}$ \\
\hline
\end{tabular}

\section{Nanocrystals}

$\begin{array}{ll}\begin{array}{l}\text { Fenofibrate } \\ \text { Megestrol acetate }\end{array} & \text { Oral } \\ \text { Nitrendipine } & \text { Oral } \\ \text { Nobiletin } & \text { Oral } \\ \text { Tranilast } & \text { Pulmonary } \\ & \\ \text { Carbendazim } & \text { Oral } \\ \text { Cilostazol } & \text { Oral } \\ \text { Curcumin } & \text { Oral } \\ \text { Danazol } & \text { Oral } \\ & \\ \text { Diclofenac Na } & \text { IV } \\ \text { Insulin } & \text { Dermal } \\ \text { Lidocaine } & \text { Oral } \\ \text { Clozapine } & \text { Dermal } \\ & \\ & \end{array}$

\section{Solid lipid nanoparticles}

Solid-in-oil nanosuspensions

Lectin-modified solid lipid nanoparticles

Solid lipid nanoparticles

Solid lipid nanoparticles

Solid lipid nanoparticles

\section{Micelles}

Block copolymeric micelles

Self-micellizing solid dispersion

Block copolymeric micelles

Block copolymeric micelles

Block copolymeric micelles

Polymeric nanoparticles

PLGA and alginate nanoparticles

PLA-PEG nanoparticles

PLGA nanoparticles

PLGA nanoparticles

Chitosan analog nanoparticles

Albumin nanoparticles

Hydrogel nanoparticles

PLGA nanoparticles

PLGA nanoparticles

Ethyl cellulose/casein nanoparticles

\begin{tabular}{|c|c|}
\hline Pilocarpine & Ocular \\
\hline Tranilast & Oral \\
\hline Camptothecin & IV \\
\hline Doxorubicin & IV \\
\hline Paclitaxel & \\
\hline Clotrimazole/econazole & Oral \\
\hline Docetaxel & IV \\
\hline Doxorubicin & IV, IP \\
\hline Rifampicin & Oral \\
\hline siRNA & Oral \\
\hline Paclitaxel & IV \\
\hline Insulin & Oral \\
\hline Glucagon & Pulmonary \\
\hline VIP derivative & Pulmonary \\
\hline Celecoxib & Oral \\
\hline
\end{tabular}

Enhanced oral bioavailability
Enhanced oral bioavailability
Enhanced oral bioavailability and
hepatoprotection
Enhanced oral bioavailability and rapid
absorption
Better anti-inflammatory effects in lung
Enhanced bioavailability and rapid
absorption
Enhanced oral bioavailability
Enhanced oral bioavailability
Improved oral bioavailability
Improved oral bioavailability

Hanafy et al., 2007

Sylvestre et al.,

Xia et al., 2010

Onoue et al., 2013

Kawabata et al., 2010; Onoue et al., $2011 a$

Jia et al., 2003

Jinno et al., 2006

Onoue et al., 2010

Wu and Benet, 2005

Improved percutaneous absorption

Piao et al., 2008

Zhang et al., 2006

Pathak and

Nagarsenker, 2009

Reddy et al., 2004

Manjunath and Venkateswarlu, 2005

Matsumura et al., 2004

Onoue et al., 2013

Watanabe et al.,

2006

Pepic et al., 2004

Improved systemic exposure,

decreased clearance

Enhanced systemic exposure, decreased clearance

Kato et al., 2012

Enhanced oral bioavailability

Extended half-life, enhanced antitumor effect

Extended half-life, Reduced distribution to heart

Improved oral bioavailability

Improved systemic distribution and gene silencing

Low inter-/intrapatient variability, tumor targeting

Improved oral bioavailability

Extended half-life and enhanced Onoue et al., 2011b bioavailability

Enhanced anti-inflammatory effects Onoue et al., 2012 Enhanced oral bioavailability
Chaturvedi et al.,

2013

Pandey et al., 2005

Hrkach et al., 2012

Sharma et al., 2004

Zhang et al., 2012

Morgen et al., 2012
Reddy et al., 2004 
TABLE 2 | Continued

\begin{tabular}{|c|c|c|c|c|}
\hline Formulation type & Drug name & Route of administration & $\begin{array}{l}\text { in vivo (Pharmacokinetics/ } \\
\text { Pharmacodynamics) }\end{array}$ & References \\
\hline \multicolumn{5}{|l|}{ Emulsion } \\
\hline Self-emulsifying drug delivery system & Cinnarizine & Oral & Improved oral bioavailability & Larsen et al., 2013 \\
\hline Self-emulsifying drug delivery system & Coenzyme $Q_{10}$ & Oral & Improved oral bioavailability & Onoue et al., 2012 \\
\hline Self-emulsifying drug delivery system & Cyclosporin A & Oral & Improved oral bioavailability & Strickley, 2004 \\
\hline Self-emulsifying drug delivery system & Simvastatin & Oral & Improved oral bioavailability & $\begin{array}{l}\text { Thomas et al., } \\
2012\end{array}$ \\
\hline \multicolumn{5}{|l|}{ Dendrimers } \\
\hline Polylysine dendrimer & Doxorubicin & IV & $\begin{array}{l}\text { Long-lasting systemic exposure, } \\
\text { enhanced accumulation in tumor } \\
\text { tissues }\end{array}$ & $\begin{array}{l}\text { Kaminskas et al., } \\
2012\end{array}$ \\
\hline Poly (amidoamine) dendrimer & Flurbiprofen & IV & $\begin{array}{l}\text { High distribution and retention in site of } \\
\text { inflammation }\end{array}$ & $\begin{array}{l}\text { Asthana et al., } \\
2005\end{array}$ \\
\hline PEGylated polylysine dendrimer & Methotrexate & IV & Prolonged systemic exposure & $\begin{array}{l}\text { Kaminskas et al., } \\
2011\end{array}$ \\
\hline Lactoferrin-conjugated dendrimer & Methotrexate & IV & Enhanced accumulation in lung & Kurmi et al., 2011 \\
\hline Poly (amidoamine) dendrimer & Piroxam & IV & Extended systemic exposure & $\begin{array}{l}\text { Prajapati et al., } \\
2009\end{array}$ \\
\hline \multicolumn{5}{|l|}{ Liposomes } \\
\hline Liposome (PC/Chol) & O-palmitoyl tilisolol & IV & High distribution in neoplastic tissue & $\begin{array}{l}\text { Kawakami et al., } \\
2001\end{array}$ \\
\hline Liposome (PC/PG) & Paclitaxel & IV & Prolonged systemic exposure & $\begin{array}{l}\text { Fetterly and } \\
\text { Straubinger, } 2003\end{array}$ \\
\hline Liposome (PC/Chol/10\% DSPEPEG2000) & Prednisolone & IV & $\begin{array}{l}\text { Increased and prolonged systemic } \\
\text { exposure }\end{array}$ & $\begin{array}{l}\text { Teshima et al., } \\
2006\end{array}$ \\
\hline Liposome (Phospholipid/Chol) & Amikacin & IV & Extended half-life of the drug in vitreous & Honda et al., 2013 \\
\hline Liposome (PC/Chol/DSPG) & Amphotericin B & IV & $\begin{array}{l}\text { Augmented systemic exposure, } \\
\text { decreased RES uptake }\end{array}$ & Tomii, 2002 \\
\hline Liposome (DSPC/DSPG/Chol) & Cytarabine/daunorubicin & IV & Decreased clearance & $\begin{array}{l}\text { Feldman et al., } \\
2012\end{array}$ \\
\hline Liposome, PEGylated liposome & Doxorubicin & IV & High distribution in neoplastic tissue & Zhang et al., 2008 \\
\hline
\end{tabular}

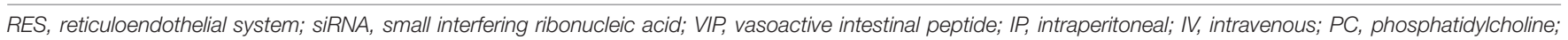

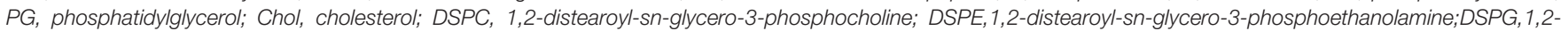
distearoyl-snglycero-3-phosphoglycerol; PEG, polyethylene glycol; PLA, polylactic acid; PLGA, poly (lactic-co-glycolic acid).

TABLE 3 | Biopharmaceutical and safety profile of nanoformulations (Onoue et al., 2014).

\begin{tabular}{|c|c|c|c|}
\hline \multicolumn{2}{|c|}{ Biopharmaceutical properties } & \multicolumn{2}{|c|}{ Safety } \\
\hline Advantages & Disadvantages & Advantages & Disadvantages \\
\hline \multicolumn{4}{|l|}{ Engineered Nanoparticles } \\
\hline $\begin{array}{l}\text { Improved systemic exposure High retention in } \\
\text { mucosal layer Several dosage routes available }\end{array}$ & $\begin{array}{l}\text { Low sustained releasing } \\
\text { potency }\end{array}$ & $\begin{array}{l}\text { Decreased gastric irritancy of } \\
\text { NSAIDs }\end{array}$ & $\begin{array}{l}\text { Toxic risk due to high } \\
\mathrm{C}_{\max } \text { cytotoxic potential }\end{array}$ \\
\hline \multicolumn{4}{|l|}{ Lipid Nanosystems } \\
\hline $\begin{array}{l}\text { Biodegradable and metabolized Specific drug } \\
\text { delivery Prolonged systemic exposure }\end{array}$ & $\begin{array}{l}\text { Rapid clearance due to RES } \\
\text { uptake Limited dosage route }\end{array}$ & Low toxicity Low antigenicity & $\begin{array}{l}\text { Cytotoxicity depending on } \\
\text { the surfactant used }\end{array}$ \\
\hline \multicolumn{4}{|l|}{ Micelles } \\
\hline $\begin{array}{l}\text { High membrane permeability High solubilizing } \\
\text { potency Improved systemic exposure }\end{array}$ & $\begin{array}{l}\text { Low sustained releasing } \\
\text { potency }\end{array}$ & Low immunogenicity & $\begin{array}{l}\text { Toxic risk due to high } \mathrm{C}_{\max } \\
\text { Cytotoxicity depending on } \\
\text { used surfactant }\end{array}$ \\
\hline \multicolumn{4}{|l|}{ Polymeric Nanoparticles } \\
\hline $\begin{array}{l}\text { Stable in vivo drug release Long duration of } \\
\text { action }\end{array}$ & $\begin{array}{l}\text { Need to avoid initial burst } \\
\text { Limited dosage route }\end{array}$ & Low immunogenicity & $\begin{array}{l}\text { Need to be removed } \\
\text { surgically for } \\
\text { non-degradable polymers }\end{array}$ \\
\hline \multicolumn{4}{|l|}{ Dendrimers } \\
\hline $\begin{array}{l}\text { Controlled release High solubility Specific rug } \\
\text { delivery }\end{array}$ & Limited dosage route & Low immunogenicity & Hemototoxicity \\
\hline
\end{tabular}


The drug to be delivered may be encapsulated, adsorbed or chemically linked to the surface of the NPs (Sahoo et al., 2017). The residence time of these NPs in systemic circulation can be increased by the surface modification either with physical adsorption or covalent binding of hydrophilic polymers such as PEGs and polysaccharides, whereas the inclusion of tissue-specific ligands facilitates targeted delivery to the brain (Mohamed and Van Der Walle, 2008; Wilson et al., 2008). It has been established that coating of poly (n-butylcyanoacrilate) (PBCA) NPs with $1 \%$ polysorbate 80 (PS80) amplified the concentration of rivastigmine or tacrine drug inside the brain as compared with free drug and selectively targeted to the CNS for $\mathrm{AD}$ reducing the hepatic or gastrointestinal side-effects coupled with conventional treatment approach (Wilson et al., 2008). Another study proved that dalargin containing PS80coated PACA nanoparticles was capable to cross the BBB and produce its antinociceptive effect, after oral administration (Das and Lin, 2005). A possible mechanism of such delivery is adsorption of PS80-coated PACA nanoparticles on ApoE and $\mathrm{B}$ from the bloodstream upon intravenous injection followed by transcytosis across $\mathrm{BBB}$ using the low-density lipoprotein receptors (Kreuter, 2013). PLGA nanoparticles exhibits good carrier for delivering drugs across $\mathrm{BBB}$. In vivo distribution of vanlafaxine loaded PLGA nanoparticles against depression was tested in C57/bl6 mice and in vitro BBB model using hCMEC/D3 cell. They observed that transferring receptor mediated PLGA nanoparticles have better biodistribution in brain via intranasal administration and not affected by P-gP pump efflux enhacing functionalized nanoparticles concentration in the basolateral side after $24 \mathrm{~h}$ via receptor mediated endocytosis (Cayero-Otero et al., 2019).

\section{Solid-Lipid Nanoparticles}

Solid-lipid nanoparticles (SLNs) are attracting major attention as novel drug carriers nowadays and are at the forefront of the rapidly emerging nano-delivery system (Kreuter et al., 2002). These are aqueous colloidal nanocarriers system which are composed of physiological lipid (triglycerides, fatty acids, steroids, and waxes, etc.), dispersed in water or in an aqueous surfactant solution and possess the ability to get solidify upon cooling (Barchet and Amiji, 2009; Mukherjee et al., 2009). A number of efforts have been made to increase the drug loading capacity and long-term stability of SLNs, one such effort being the development of nanostructured lipid carriers (NLCs) by amalgamation of spatially dissimilar lipids or blending solid lipids with liquid lipids. Modification of SLNs with PEG increases penetration to $\mathrm{BBB}$ and enhances drug delivery to the CNS as demonstrated by a comparative study of SLNs and PEGmodified SLNs loaded with antitumor drugs like camptothecin and doxorubicin (Blasi et al., 2007; Wong et al., 2007). SLNs are preferred more over PNPs due to numerous advantages such as low intrinsic cytotoxicity, physical stability, shielding of labile drugs from degradation, controlled release which provide them potentiality to be used as a brain drug delivery system, especially for brain tumors (Laquintana et al., 2009). The possible mechanism of their delivery across BBB may be endocytosis, transcytosis which takes place in the endothelial cells lining the blood capillaries in brain or permeation through the tight junctions between endothelial cells. Furthermore, the adsorption of a plasmatic protein such as the apolipoprotein E, onto SLNs surface could facilitate its uptake into brain mediated by adherence to the endothelial cells of the BBB (Kreuter et al., 2002; Reddy and Venkateswarlu, 2004; Blasi et al., 2007).The above approach has been used for the encapsulation of a broad range of drugs to achieve target-specific delivery of drugs across BBB. Sterylamine-based SLNs containing clozapine, an antipsychotic drug have been fabricated and demonstrated to deliver the drug successfully inside the brain after intravenous and intraduodenal administration (Manjunath and Venkateswarlu, 2005). Other examples of drug loaded SLNs include quercetin loaded SLNs to treat AD (Dhawan et al., 2011), atazanavir loaded SLNs for treatment of HIV-encephalitis (Chattopadhyay et al., 2008). Recently, it was observed that riluzole-loaded SLNs have greater efficacy than free riluzole in amyotrophic lateral sclerosis (ALS) rat model developed by immunization using the experimental allergic encephalomyelitis (Bondì et al., 2010).

\section{Nanoemulsions}

Nanoemulsions are either oil-in-water (O/W) or water-inoil (W/O) colloidal particulate systems that are composed of edible oils, surface-active agents (surfactants) and water, having a size range 100-500 $\mathrm{nm}$ (Sarker, 2005; Lovelyn and Attama, 2011). Recently, their use as drug delivery system has been promoted heavily to tackle several problems associated with conventional delivery systems such as low bioavailability, poor targetability, and penetrability across BBB (Lovelyn and Attama, 2011). Various oils and surface modifiers that are used in preparation are the key determinants of the versatility of nanoemulsions (Sarker, 2005). For instance, fabrication of nanoemulsions with oils that are rich in omega3 polyunsaturated fatty acids (PUFA) imparts specific properties to nanocarriers for overcoming biological barrier, including the $\mathrm{BBB}$, therefore help in achieving the rapid distribution of drugs to peripheral sites, especially the brain (Shah et al., 2013). The nanoemulsion system containing pine-nut oil significantly increased the oral bioavailability of paclitaxel (Tiwari and Amiji, 2006).

\section{Dendrimers}

Dendrimers are the emerging polymeric structures that are known for their defined structures, and versatility in drug delivery. They have 3-D symmetrical architecture possessing an inner core from which a number of hyperbranches, known as "generations," having various chemical functional groups at the peripheral terminal surface arise due to which they can be easily functionalized with different ligands (Tripathy and Das, 2013; Xu et al., 2013; Leiro et al., 2018; Dias et al., 2020). Depending upon the generations, complexity and building block materials, a wide range of dendrimers has been developed among which polyamidoamine (PAMAM), polypropylene imine (PPI), and polylysine dendrimers are of intense interest for both hydrophobic and hydrophilic drug molecules delivery. The high molecular weight hydrophilic/hydrophobic entities either physically 


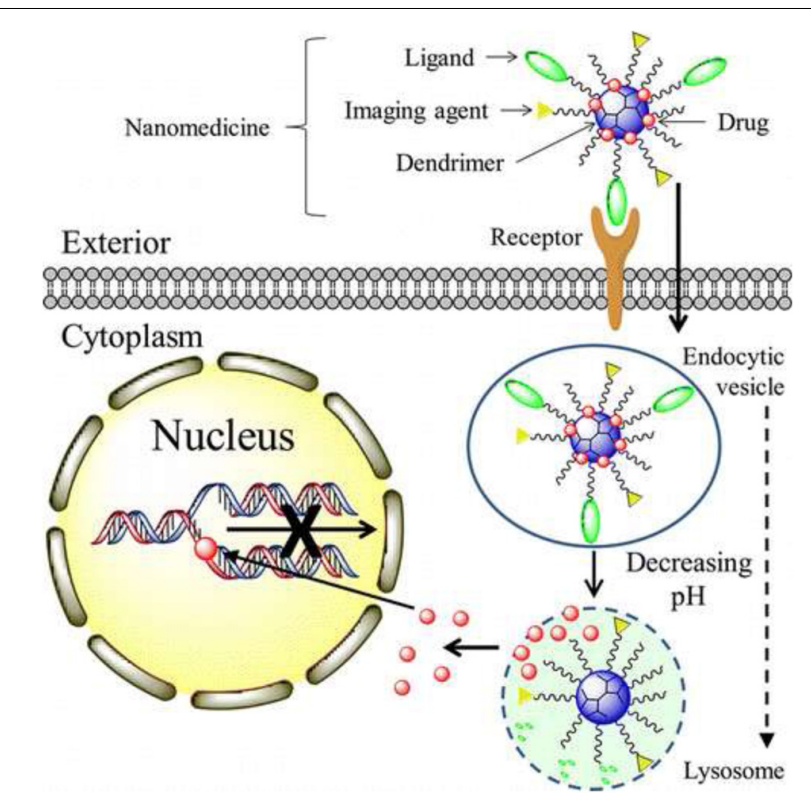

FIGURE 3 | Mechanism of nanotherapeutics, such as methotrexate and doxorubicin, delivery by dendrimers for brain tumor. Reproduced with permission from Xu et al. (2013). Copyright @ 2014, American Chemical Society. entrap/conjugate by host-guest interactions or covalently bound with peripheral functional groups of dendrimers to form a dendrimer-drug complex (Tripathy and Das, 2013). Although, dendrimers have wide application in drug delivery, yet their use in biological systems is limited due to complex synthetic procedures and toxicity issues (Kaminskas et al., 2011; Tripathy and Das, 2013).

Nowadays, as a drug carrier, dendrimers are given more preference over traditional polymers due to various features such as high aqueous solubility, biocompatibility, polyvalency, and precise molecular weight which make them amenable for targeted drug delivery in the brain (Duncan and Izzo, 2005; Tomalia, 2005). They have shown potential as carriers of drugs, therapeutic nucleic acids, peptides and proteins, contrast agents for CNS disorders treatment, imaging, and diagnosis (Xu et al., 2014; Figure 3). Aso et al. (2019) synthesized Poly (propylene imine) dendrimers core and maltose-histidine shell (G4HisMal) and check their biocompatibility and ability to penetrate $\mathrm{BBB}$, they were tested it against $\mathrm{AD}$ and found their high ability to cross $\mathrm{BBB}$ with significant biocompatibility showing memory protection in transgenic mice model of Alzheimer disease via synapse protection. The in vitro efficacy and in vivo targeting capability of hydroxyl-G6 PAMAM dendrimer9-amino-minocycline conjugate (D-mino) was checked, additionally D-mino was assessed for anti-inflammatory and antioxidant activity in lipopolysaccharides-activated murine microglial cells. The rapid uptake, decreases inflammatory cytokines and nitric oxide levels suggested that dendrimers formulation are having high efficacy as compare to free drug, further it was observed that fluorescently labeled dendrimer conjugate (Cy5-D-mino) crosses the blood brain barrier much efficiently than free drug (Sharma et al., 2017; Figure 4).

Targeted delivery by dendrimers can be achieve by attaching target ligands such as transferrin family ligands having an affinity for TRs, mAbs against specific receptors, lectins such as wheat germ agglutinin (WGA), etc (Tomalia, 2005). The dendritic approach has been applied to improve the solubility and oral absorption of various drugs such as camptothecin (CPT), by conjugating drugs with PAMAM dendrimers (Sadekar et al., 2013). Recently, it was demonstrated that cisaconityl linkage, an acid-sensitive linkage, in PAMAMPEG-Doxorubicin (DOX) conjugates followed an acid-triggered release kinetics which gradually increases with increasing degree of PEGylation and simultaneously imparts following properties to the conjugates: reduced hepatic and splenic accumulation, prolonged circulation time, and enhanced tumor buildup of the conjugates (Zhu et al., 2010a,b).

\section{MECHANISM OF ACTION OF DRUG RELEASE}

The physiochemical properties of drug loaded nanocarrier like hydrophilicity, surface charge and targeting ligands of nano carrier is the deciding factor for the adsorption on the brain capillary endothelial cells. Surface charge like positive nature of the nanomaterials interacts with the negative surface charge of endothelial cells of brain, due to electrostatic interactions between carrier and cells, secondly lipophillic nature of nanocarriers also enhance and facilitates adsorption process (Markoutsa et al., 2011; Lien et al., 2012). These approaches reduces the clearance of nanocarrier by the fixed macrophages of the mononuclear phagocytic system (MPS), Once, the nanomaterials get absorbs either through targeting low density lipoprotein receptors present on the microvessel brain capillary endothelial cells (Kim et al., 2007) by means of normal endocytosis and transcytosis, desorption occurs and reenter into the blood stream, where drug loaded nanocarrier releases its encapsulated or adsorbed drug on the surface of blood brain barrier and further diffuses into brain parenchyma. The average size of human cells is 10$20 \mu \mathrm{m}$, where as the minimal diameter of blood capillaries are 6-9 $\mu \mathrm{m}$, due to their nano size ranges nanomaterials get easily transported and internalizes by brain capillary endothelial cells via endocytosis and transcytosis mechanism of transport (Vilella et al., 2014). The adsorbed drug-carrier conjugates is endocytosized by the cells, at times followed by exocytosis, and further penetration of the nano carrier into the cells or brain parenchyma occurs.

The mechanism of drug delivery by nanotechnology is not still well-explored, however, various suggestions have been put forward to suggest possible mechanisms. Though the uptake of nanocarriers along with drugs into the brain has been proposed to occur by following six mechanisms (Kreuter, 2001, 2013; Wohlfart et al., 2012): 

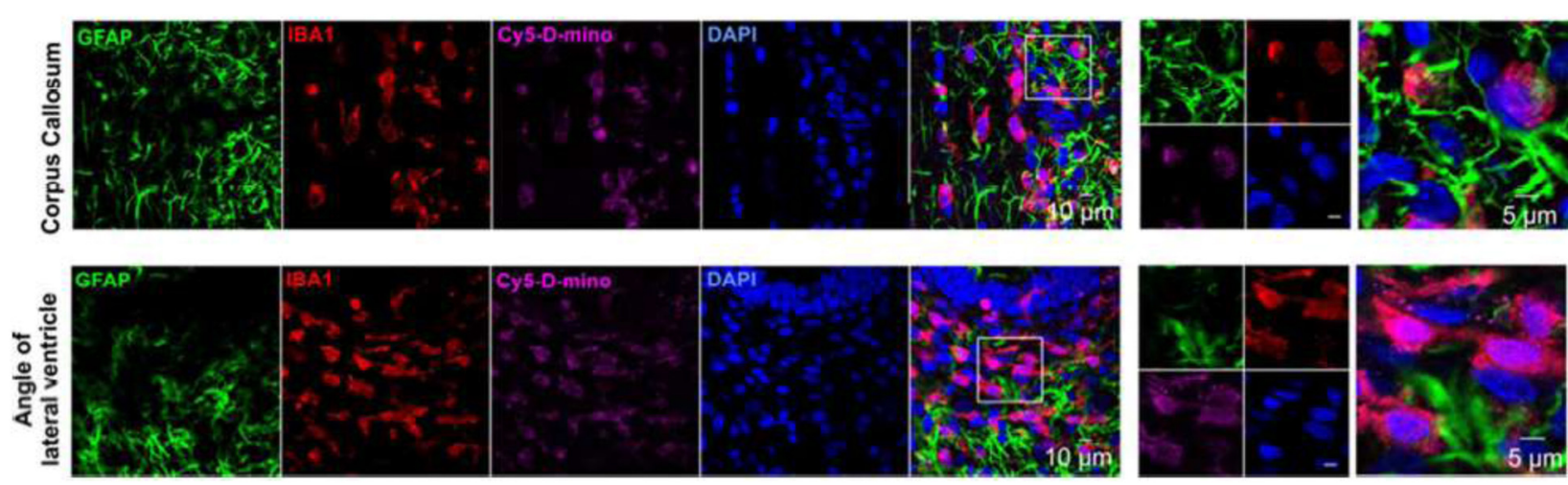

FIGURE 4 | In vivo cellular localization of Cy5-D-mino. The endotoxin kits with Cerebral Palsy $(n=3)$ received Cy5-Dmino (55 mg/kg, i.v) on Post Natal Day 1 and sacrificed 24 h post-injection. Brain slices contain Cy5-D-mino (magenta) were co-stained with GFAP (astrocyte marker, green)/IBA1 (microglial marker, red)/DAPI (blue). Cy5-D-mino is mainly co-localized with activated microglia at the corpus callosum and angle of lateral ventricle. The images on the right panels are the higher magnification of the region of interest marked with the boxes on the left panels. Reproduced with permission from Sharma et al. (2017). Copyright @ 2017, American Chemical Society.

(i) Increased transport across the endothelial cell layer facilitated by higher concentration gradient due to increased retention of the nanocarriers in the brain blood capillaries with an adsorption to the capillary walls. Since the diffusing drug can be effluxes out by various transporters such as P-gp, it is not a good mechanism to achieve a sufficient amount of drug inside the brain to elicit a relevant pharmacological response.

(ii) Inhibition of the efflux system particularly P-gp.

(iii) Toxicity to the brain vasculature.

(iv) Solubilization of the endothelial cell membrane lipids due to general surfactant effect followed by membrane fluidization and enhanced drug permeability across the BBB.

(v) Permeation of nanocarrier system through the tight junctions after the opening of them.

(vi) Endocytosis and transcytosis phenomenon through the endothelial cell layer.

Since the entry of foreign entities in CNS is strictly prohibited by $\mathrm{BBB}$, only selective one gets access to the brain. They get entry into the brain either by passive, gradient-dependent (passive targeting) or active, energy-dependent (active targeting) pathways. As the passive movement of water solutes through the clefts between adjacent cells (paracellular transport) is negligible at physiological conditions due to the presence of tight junctions as well as the early phases of neurological disease do not involve any defects in BBB to allow drug transport, implication of this transportation pathway for delivery of drug-loaded nanocarrier is not a successful approach. As an alternative, consideration should be given to the transportation of nanocarriers per se through the endothelial cells (transcellular transport). The nanocarriers of size less than $500 \mathrm{Da}$ having the ability to absorb inside cells are suitable for transcellular transportation (Georgieva et al., 2014). Transcytosis process especially the receptor-mediated transcytosis across $\mathrm{BBB}$ is an attractive strategy to deliver drugs into CNS. It requires vector for the delivery of nanocarrier between the apical and basolateral surface in polarized cells. Receptor-mediated internalization of cargo followed by vesicular transport is a suitable option as nano-delivery systems of size 100-200 nm range can be easily accommodated in these transport vesicles. Three distinct steps are involved in overall transcytosis process: endocytosis of the nanocarrier at the plasma membrane, trafficking of intracellular vesicles toward the opposite surface followed by exocytosis (Rappoport, 2008; Pardridge, 2012; Georgieva et al., 2014).

Internalization via phagocytic mechanism occurs by various pathways among which clathrin-dependent and caveolindependent pathways are the major one:

(i) Clathrin-mediated endocytosis happens in all mammalian cells. As the nanocarrier binds with a specific receptor on the cell membrane, it triggers the polymerization of clathrin-1, a cytosolic protein underneath the plasma membrane forming an inward budding leading to the internalization of cargo (Rappoport, 2008). After wrapping of the nano-delivery system, the GTPase activity of dynamin pinches off the inward budding resulting into the formation of clathrin-coated vesicles (Pucadyil and Schmid, 2009). The clathrin coat shed off during the movement of vesicles inside cytosol with the help of energy provided by actin, leading to the formation of early endosomes as detected by early endosome antigen-1 (EEA-1), a typical marker. The early endosome delivers their content to late endosomes and finally to the lysosomes where it is degraded off. The compartmental $\mathrm{pH}$ gradually falls during the transition of late endosomes to the lysosomes, which triggers the release of drug from nano-vehicle and eventually the drug is released at the desired site (Mellman, 1992; Georgieva et al., 2014).

(ii) Another well known pathway for delivery of nanocarriers inside the brain is caveolar pathway. This pathway is similar to the clathrin-mediated pathway in most of the 


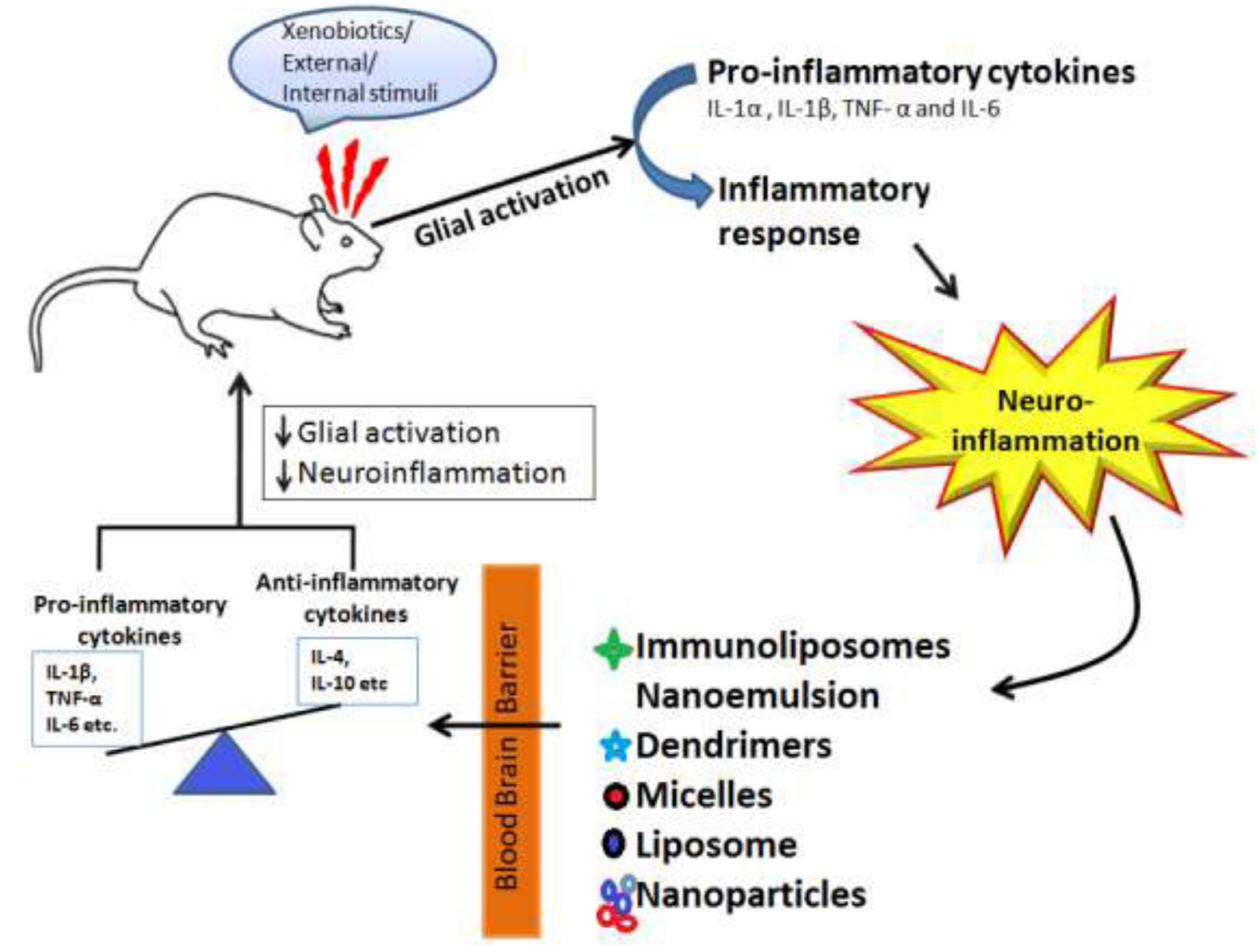

FIGURE 5 | Schematic representation of nanotechnology-based therapy for CNS disorders.

aspects but there is possibility to escape lysosomal delivery which is a key factor that makes it different from the clathrin-mediated pathway (Mcintosh et al., 2002). For the same difference, this pathway augments the delivery of drugs at the targeted site and therefore improve the therapeutic value of drugs, thus targeting receptors associated with caveolae may prove good approach for transcellular delivery of the nanocarriers. Caveolae are flask-shaped plasma membrane invaginations and caveolin protein, present in three isoforms in mammalian cells: caveolin-1, caveolin-2, and caveolin-3 play a dominating role in this transportation pathway (Kou et al., 2013). As soon as the nanocarriers binds to the caveolar receptor, it is internalized forming a vesicular structure known as cavicle, by the involvement of dynamin in a similar way as in clathrin-mediated pathway. The cavicle moves inside the cytosol with the help of energy derived from actin and get fused with caveosomes which have neutral $\mathrm{pH}$ and then head toward the endoplasmic reticulum (ER). It is considered that nanocarrier from ER penetrates into the cytosol and finally gain access to the nucleus through the nuclear pore complex (Kasamatsu and Nakanishi, 1998; Parton and Simons, 2007; Kou et al., 2013).

\section{APPLICATIONS OF NANOTECHNOLOGY IN CNS DISORDERS}

Nanotechnology has revolutionized the field of treating various neurological disorders and has provided a number of new approaches that have shown potential for treating neurodegenerative disorders like $\mathrm{AD}, \mathrm{PD}$, stroke, epilepsy, $\mathrm{HD}$, and brain tumor. Molecules are nano-engineered so that they have an ability to traverse the $\mathrm{BBB}$, target the specific cell or signaling pathway, act as a carrier for gene delivery. Besides delivery of therapeutic drugs, nanotechnology has also gained the interest of researchers for delivery of radiocontrast agents, imaging agents for diagnosis purpose. Figure 5, is the schematic representation of nanotechnology-based therapy for CNS disorders depicted that when an external stumuli or in diseased conditions glial activation occurs which leads to neuroinflammation and leads to imbalance between 
pro-inflammatory and (IL- $1 \beta, \mathrm{TNF}-\alpha$, and IL-6) and antiinflammatory cytokines (IL-4, IL-10, etc.), here the authors are showing through schematic representation that drugs loaded with nanoformulations such as immunoliposomes, dendrimers, micelles, liposomes, and nanoparticles due to their small size and specific targeting ability stabilizes and modulate the release of drugs to cross the blood brain barrier and restores the healthy conditions via reducing neuroinflammation and glial cells activation.

\section{Alzheimer's Disease}

Alzheimer's disease is a slowly progressive neurodegenerative disorder, and is the main culprit for dementia syndrome. Pieces of evidence state that its incidence and prevalence rate is more common in elder persons (Sloane et al., 2002). Amyloid- $\beta$ plaques and Tau protein hyper-phosphorylation are considered as hallmarks of AD (Kumar and Singh, 2015). The degeneration of nervous tissue in $\mathrm{AD}$ starts years back of the actual appearance of the symptoms of the disease. The conventional treatment approaches are not able for complete treatment of disease, thus the inability of orally administered drugs such as tacrine, rivastigmine, etc. to treat the disease, opens the door for the application of nanotechnology for $\mathrm{AD}$ treatment.

A wide range of nano-formulations has been fabricated to have a beneficial impact on $\mathrm{AD}$ patients. It was demonstrated that PEG stabilized nanomicelles composed of phospholipids inhibit $A \beta$ aggregation and attenuate $\mathrm{A} \beta$-induced neurotoxicity in SHSY$5 Y$ human neuroblastoma cell line in vitro (Pai et al., 2006). The in vitro study demonstrated the ability of phytochemical curcumin to reduce $A \beta$ oligomerization and cytotoxicity, but poor bioavailability was shown when injected into mice (Yang et al., 2005). The nanoliposomal formulation of curcumin enhanced its bioavailability without disturbing its ability of inhibiting $A \beta$ aggregation (Taylor et al., 2011).

Since the increased level of metal ions, such as copper, also contributes in the pathology of $\mathrm{AD}$, use of chelating agents is another approach for AD management (Lovell et al., 1998). Microemulsion nanoparticles loaded with copper chelator d-penicillamine were found to have capability of crossing the $\mathrm{BBB}$ and dissolving the pre-existing $\mathrm{A} \beta$ aggregates in vitro (Cui et al., 2005).

Oxidative damage, another key factor in the pathology of $\mathrm{AD}$, suggests the applications of antioxidants in $\mathrm{AD}$ management. Fullerene derivatives, the potent free-radical scavengers, have been found to possess neuroprotective action against glutamate receptors induced excitotoxicity. On the other hand ability of fullerene for neuroprotection, in vitro as well as in vivo, against $\mathrm{A} \beta$ toxicity has not been proved, yet its ability to inhibit $\mathrm{A} \beta$ peptide fibrillization and prevention of $A \beta$-induced cognitive impairments after intraventricular administration suggests its beneficial role in AD treatment (Podolski et al., 2007).

Marked deficiency of acetylcholine (ACh) neurotransmitter is another important feature in the pathology of $\mathrm{AD}$. Due to its faster decomposition in blood, the direct injection of free $\mathrm{ACh}$ is not effective for reversal of the imbalance in ACh. Thus, nanotechnological approach has been used for delivery of ACh in the brain to achieve balanced ACh level. The ACh loaded in carbon nanotubes have been found to restore the significant cognitive functions to pre-AD level in a kainic-acid induced mouse model as compared to free ACh (Yang et al., 2010).

\section{Parkinson's Disease}

Parkinson's disease, illustrated by loss of dopaminergic neurons in the substantia nigra of the midbrain and the generation of $\alpha$-synuclein aggregates (Lewy bodies), is the next most common neurodegenerative disorder worldwide after AD. Nowadays, it is considered that pathology of PD is not just limited to a particular part of the brain but it involves various other regions of the brain, neurotransmitters such as imbalance in ACh and dopamine, and protein aggregates other than Lewy bodies (Kalia and Lang, 2015). The manifestations of PD involve motor symptoms like tremor, speech, writing changes and non-motor symptoms like cognitive, behavioral, and autonomic changes.

The current medication treatments available for PD do not cure nor alleviate the progression of the disease but aim to provide the symptomatic relief to the patients, and beside this, the inability of available drugs to cross BBB is another challenge for treating PD. As a result, development of innovative and more effective therapy is the need of hour. This problem can be addressed by the nanotechnological approach, as it has shown great potential to reverse or limit the disease states, promote the functional regeneration of damaged neurons, provide neuroprotection and facilitate the delivery of drugs overcoming the BBB (Modi et al., 2010; Soursou et al., 2015).

Gene delivery approach has been intensely exploited in the perspective of PD. The conventional gene delivery studies involve viral vectors, but they were commonly associated with toxicity and immunogenicity problems while nanotechnological approach was found to be devoid of such type of problems (Witt and Marks, 2011). The PEG and polyethyleimine nanogels complexes with antisense oligonucleotides demonstrated the efficient crossing of $\mathrm{BBB}$ in vitro and also delivered the oligonucleotides to the brain, when injected intravenously, more efficaciously particularly when the gels were functionalized with insulin or Tf molecules (Vinogradov et al., 2004). In another study on 6-hydroxydopamine (6-OHDA) model of $\mathrm{PD}$ in rats, the striatal tyrosine hydroxylase enzyme activity was restored with reversal of motor impairment, after a single intravenous administration of tyrosine hydroxylase-encoding plasmids and Tf receptor antibody conjugated PEGylated liposomes (Zhang et al., 2003). Recent study has confirmed that nerve growth factor (NGF) bound PBCA nanoparticles (Kurakhmaeva et al., 2009) and L-Dopa encapsulated nanoparticles cross $\mathrm{BBB}$ and alleviate basic symptoms of PD (Mohanraj et al., 2013).

mPEG PLGA nanoparticles of size range $70 \mathrm{~nm}$ i.e., Schisantherin A (SA) was used against Parkinson diseases (PD) in zebrafish larvae where SA encapsuled in nanoparticles formulation that extended SA circulation in the blood stream and consequently an increased brain uptake and reported as potentially efficacious for the treatment of PD. It was found that nanoparticulate delivery of SA was much more effective than SA suspension alone. In addition, the SA-NPs exerted strong 
neuroprotective effects in zebrafish and cell culture model of PD (Chen et al., 2017).

\section{Huntington Disease}

Huntington disease (HD) is described by preferential loss of neurons in striatum and other brain regions leading to progressive motor, cognitive, and psychiatric manifestations. It occurs due to monogenic mutation in the exon 1 of huntingtin gene which leads to polyglutamine (poly Q) expansion and causes misfolding and aggregation of huntingtin protein (HTT) in the brain (Bates et al., 2015). Several studies confirm the involvement of astrocytes in HD. Brains of $\mathrm{HD}$ patients and mouse models of $\mathrm{HD}$ demonstrates accumulation of mutant HTT in striatal astrocytes which ultimately leads to age-dependent HD-like pathology and premature mortality (Bradford et al., 2009). Symptomatic and protective treatment strategies are available for HD but none of them are efficacious to completely cure the disease. Currently, tetrabenazine is FDA approved drug for the symptomatic treatment of HD.

A possible linkage between oxidative stress and neurodegenerative disorders such as $\mathrm{HD}$ has been shown in literature (Kim et al., 2015; Liu et al., 2017). Therefore, antioxidant therapy can be employed in HD to prevent oxidative stress. Fullerenols have ability to clear free radicals and reduce oxidative burden to cell. Jin et al reported their antagonistic behavior on glutamate receptors and therefore they can be implicated for neuroprotective use (Jin et al., 2000).

Nitrendipine is a calcium channel blocker that declines the incidences of dementia (upto 50\%) in HD in a period of 2 years. Being hydrophilic, this drug has permeability issues and thus poorly crosses BBB. In a study, SLNs of nitrendipine were prepared and a comparison in the uptake of bulk drug and nanoformulation was done. The results demonstrated the higher uptake of drug when it was encapsulated in SLNs (Manjunath and Venkateswarlu, 2006). In another study, short-interfering RNA (siRNA) encapsulated cyclodextrin nanoparticles were found capable to reduce expression of HTT mRNA both in vivo as well as in vitro (Godinho et al., 2013).

\section{Multiple Sclerosis}

Multiple sclerosis (MS) is a progressive autoimmune and inflammatory disease. It is a multifactorial disease in which body's immune cells attack on the nervous system. It involves various pathogenic mechanisms leading to demyelination of myelinated axons which results into slow conduction of nerve signal. There are evidences which suggest mutual interplay of microglial, astrocyte and T-cells beside demyelination (Khare et al., 2014; Ojha and Kumar, 2018). It is diagnosed on the basis of clinical findings, magnetic resonance imaging (MRI) and examination of Cerebrospinal fluid (CSF) (Khare et al., 2014). The prevalence rate of MS ranges $2-150$ per 100,000 people and females are more susceptible than males (Jones et al., 2008). MS attack disrupt BBB in the section of brain or spinal cord from where peripheral $\mathrm{T}$ lymphocytes gain access to brain and attack the myelin gradually leading to demyelination (Zeis et al., 2009).
In past few years, advancements in nanotechnology have shown promising outcomes in diagnosis and treatment of MS. The theranostic approach has been found to possess potential applications in the field of medical care and cure of MS (Singh et al., 2012). The interaction of carbon nanotubes with stem cell provides new opportunities in nerve tissue engineering to explore and add to cell behavior (Huang et al., 2012). It provides alternative ways to treat MS pathology related to non-genetic manipulations of signaling pathways in vivo (Nunes et al., 2012). In a preclinical study, ciliary neurotrophic factor (CNTF) loaded microcapsules demonstrated in situ sustained delivery of CNTF upon encapsulation into polymers. This formulation was found to be devoid of any immune response and cytotoxic effect (Aebischer et al., 1996).

Beside role in therapeutics, nano-based approach also has implications in diagnosis of MS. DNA-carrier gold NPs based barcode assay is highly sensitive assay to detect biomarkers in CSF or diseased brain. Since radio diagnosis is a gold technique for detection of MS, this diagnostic assay may be highly useful in diagnosis of MS (Georganopoulou et al., 2005). All the recent developments made in nanotechnology opens a new door for diagnosis and treatment of MS pathologies.

\section{Tumor}

Brain tumors, like other body parts tumors, may be benign, originating and residing within the brain, or metastatic, originating from a tumor outside the CNS, among which glioblastoma multiforme (GBM) - a malignant glioma, is the most prevalent. They are among the most challenging disease to treat due to poor prognosis, diagnosis, high recurrence rate, and availability of limited number of convenient methods to transport anti-cancer drugs across BBB in effective concentration (Sanai and Berger, 2008; Özdemir et al., 2017). Current treatments available are just palliative, involving united approaches of surgical debulking with radiotherapy and chemotherapy, which are not sufficient for the complete treatment, and also the reversal to the tumor state again is most common (Özdemir et al., 2017). The inability of conventional methods has provided a platform for the development of innovative nanotechnological approach as a novel imaging tool or to improve anticancer drug delivery into tumors while minimizing its distribution and toxicity in healthy tissues (Bidros and Vogelbaum, 2009).

Owing to the ability of glioma cells to aggressively infiltrate normal brain tissue and survive from the exposure to current adjuvant therapies, it is extremely important to construct specific targeted nanoplatforms capable of delivering imaging agents directly into invasive tumor cells. Owing to the ability of glioma cells to aggressively infiltrate normal brain tissue and survive from the exposure to current adjuvant therapies, it is extremely important to construct specific targeted nanoplatforms capable of delivering imaging agents directly into invasive tumor cells. Owing to the ability of glioma cells to aggressively infiltrate normal brain tissue and survive from the exposure to current adjuvant therapies, it is extremely important to construct specific targeted nanoplatforms capable of delivering imaging agents directly into invasive tumor cells. 
Ability of glioma cells to infiltrate normal brain tissue and survive from the current adjuvant therapies opens the new door for employment of nano-based approach to deal with the glioma. Many researchers are trying to develop new nanotherapeutics approach to achieve a breakthrough in the treatment of gliomas. A broad range of nano-formulations for effective delivery of drugs across BBB has been developed and investigated ( $\mathrm{Li}$ et al., 2014). Such nanoformulations include PBCA nanoparticles loaded with methotrexate (Gao and Jiang, 2006) and temozolamide (Tian et al., 2011), and have resulted in significantly increased intracerebral drug concentration as compared with free drugs. Similarly, the SLNs of etoposide (Lamprecht and Benoit, 2006) and paclitaxel (Garcion et al., 2006), in vitro, demonstrated the enhanced inhibitory effect on proliferation of glioma cell lines more efficiently than the free drug alone. Dendrimers have also been used to deliver antineoplastic treatments to the brain. Methotrexate conjugated to polyether-copolyester (PEPE) dendrimers demonstrated improved cytotoxicity against U87 and U343 cancer cell lines in culture and this nanoformulation was able to overcome acquired resistance to the drug, suggesting its role in combating resistance to the drug in gliomas (Dhanikula et al., 2008). Doxorubicin (DOX) loaded PEGylated PAMAM dendrimers demonstrated an extended therapeutic window by hindering C6 glioma spheroid proliferation and exhibited little cytotoxicity against brain microvascular endothelial cells in vitro (He et al., 2011). For imaging purpose, NPs as contrast agents offer detailed cellular and molecular imaging and thus provide information for efficient surgical removal of gliomas. Ultra small (less than $5 \mathrm{~nm}$ in diameter) gadolinium oxide crystals have been successfully used to label glioma cells GL-261 in vivo (Hernández-Pedro et al., 2013).

In a study, scientists encapsulated an antineoplastic drug in PEG-coated hexadecyl cyanoacrylate NPs and used against glioma. They observed controlled drug release kinetics along with higher diffusion of drug across BBB as compared to bulk drug in a rat model of gliosarcoma (Brigger et al., 2002). In an another study, epidermal growth factor receptors (EGFRs)-targeted therapy explored for treatment of glioma where angiopep-2 (A2)modified cationic lipid-poly (lactic-co-glycolic acid) (PLGA) nanoparticle (A2-N) loaded Gefitinib (Ge), an EGFR tyrosine kinase inhibitor (TKI) and Golgi phosphoprotein 3 (GOLPH3)siRNA were prepared. They demonstrated that Angiopep-2modified cationic lipid polymer crosses the BBB. Gefitinib can inhibit EGFR signaling and block the autophosphorylation of critical tyrosine residues on EGFR whereas GOLPH3 siRNA downregulate GLOPH3 expression (Ye et al., 2019).

\section{Epilepsy}

Epilepsy, a CNS disorder, is characterized by an abnormal increase in brain electrical activity that may be either limited to the focal area or spread throughout the brain, resulting in partial or generalized seizures, respectively (Jabir et al., 2015). The current treatment methods, having the aim of diminishing the seizure frequency and severity while producing the minimum toxic effects to the brain and other tissues of the body, are almost failures due to various hurdles, such as the inability of drugs to cross $\mathrm{BBB}$, drug resistance and recurrence of disease after drug discontinuation. Various strategies such as nanobased approach, prodrugs, efflux pump inhibition, opening of BBB by hyperosmolar solution, direct drug delivery to the ventricles and cortex, gene therapy, have been developed for epilepsy treatment, but among these all, the nano-technological approach has shown great potential for overcoming all the major hurdles in epilepsy treatment including, crossing of BBB and targeted delivering of drugs at their therapeutic concentration (Bennewitz and Saltzman, 2009).

Solid lipid nanoparticles loaded with carbamazepine (Samia et al., 2012) and PLGA nanoparticles loaded with $\beta$-carotene (Yusuf et al., 2012) have been found to show more potential for anticonvulsant effect than nanoemulged loaded carbamazepine and polysorbate- 80 coated PLGA nanoparticles, respectively. In a rat model, liposomal muscimol formulation (Kohane et al., 2002) has been reported to suppress focal seizures while producing minimal histological alterations, and amiloride loaded liposomes (Ali et al., 2007) demonstrated higher anticonvulsant potential in comparison to the free drug in a mice model. In another study on a rat model, it was found that the subcutaneous administration of the ethosuximide loaded chitosan nanocapsules decrease the spike wave discharge. Because of their ability to provide stable release of the drug, these nano-formulations can be fabricated as depot drug delivery systems for long-term use of antiepileptic drugs (Hsiao et al., 2012).

\section{Stroke}

Stroke, an acute CNS disorder, is characterized by the disruption to the vasculature supplying the brain, resulting into sudden symptoms, within seconds to hours, which usually depends on the fraction of the brain involved and the severity. There are two main types of stroke: Ischemic stroke, contributing $87 \%$ of total stroke, comprising of lacunar, cardioembolic and cryptogenic stroke, and the hemorrhagic stroke, having $13 \%$ contribution to the total stroke, comprising of $10 \%$ intracerebral and 3\% hemorrhagic stroke (Sacco et al., 2013). It is among the principal cause of mortality and morbidity, regardless of the availability of a number of treatment approaches, due to various challenges in drug treatment, which demands the development of new therapeutic approaches. The nanotechnological approach has shown great potential to overcome the major hurdles in stroke management and has provided a useful platform for the development of novel therapeutic methods for treatment (Sarmah et al., 2017).

Free radicals, which result in cellular and tissue damage, are considered as main contributing factors in the pathology of ischemic brain disease. The role of this contributing factor can be limited by the use of nano-therapeutic approach. Cerium oxide nanoparticles were demonstrated to possess antioxidant properties that supported cell survival and reduced the production of free radicals, as well as, were found to be non-toxic to neuronal (HT22) and macrophage (RAW164) cell lines (Schubert et al., 2006). In another study, xenon gas, a small molecule that can readily cross the $\mathrm{BBB}$ and has favorable neuroprotective properties, was loaded into liposomes and administered for up to $5 \mathrm{~h}$ after stroke onset with an 
TABLE 4 | Nanocarriers for neuroprotective therapy in acute ischemic stroke.

\begin{tabular}{|c|c|c|c|c|c|}
\hline Nanocarriers & $\begin{array}{l}\text { Types of } \\
\text { nanomaterials }\end{array}$ & Drugs/Agents & Targeting ligands & Outcomes & References \\
\hline \multirow[t]{5}{*}{ PNPS } & PLGA & $\begin{array}{l}\text { Tissue factor } \\
\text { specific siRNA }\end{array}$ & EGFP-EGF1 & Efficient RNA interference & Chen et al., 2013 \\
\hline & $\begin{array}{l}\text { Glutathione coated } \\
\text { PLGA-b-PEG }\end{array}$ & Thyroid hormones & Glutathione & Protection against ischemic damage & Mdzinarishvili et al., 2013 \\
\hline & PLGA & $\begin{array}{l}\text { PEGylated } \\
\text { epidermal growth } \\
\text { factor, } \\
\text { erythropoietin }\end{array}$ & & $\begin{array}{l}\text { Attenuation of inflammatory response } \\
\text { and improved neurogenesis }\end{array}$ & Wang et al., 2013 \\
\hline & Chitosan & bFGF & Transferrin & Reduced infarct volume & Yemisci et al., 2015 \\
\hline & Gelatin & Osteopontin & & $\begin{array}{l}\text { Reduced infarct volume and extended } \\
\text { therapeutic volume }\end{array}$ & Joachim et al., 2014 \\
\hline \multirow[t]{3}{*}{ Liposomes } & $\begin{array}{l}\text { Cholesterol, } \\
\text { PEG2000-PE }\end{array}$ & Minocycline & & $\begin{array}{l}\text { Reduced TNF- } \alpha \text { induced MMP-9 } \\
\text { release }\end{array}$ & Xing et al., 2012 \\
\hline & $\begin{array}{l}\text { DPPC, cholesterol, } \\
\text { PEG2000-PE, } \\
\text { Egg-PC }\end{array}$ & Xenon & & Reduced infarct size & Peng et al., 2013 \\
\hline & $\begin{array}{l}\text { DSPC, DPPC, } \\
\text { cholesterol }\end{array}$ & Tacrolimus & & $\begin{array}{l}\text { Reduced cerebral cell death, } \\
\text { ameliorated motor function deficits }\end{array}$ & Fukuta et al., 2015 \\
\hline \multirow{2}{*}{$\begin{array}{l}\text { Metal and } \\
\text { metal oxide }\end{array}$} & & Platinum & & ROS scavenging & Takamiya et al., 2012 \\
\hline & & Cerium oxide & & ROS scavenging & Estevez et al., 2011 \\
\hline
\end{tabular}

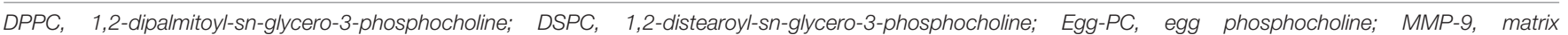

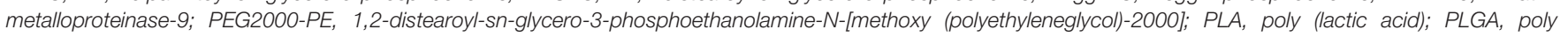
$(D, L$-lactide-co-glycolic acid); $R O S$, reactive oxygen species.

optimal dosage range of $7-14 \mathrm{mg} / \mathrm{kg}$ and found to diminish infarct size in a rat model (Peng et al., 2013). Table 4 showing different types of nanocarriers used in acute ischemic stroke conditions.

\section{NANOTECHNOLOGY BASED DELIVERY OF NEUROPROTECTIVE DRUGS}

Free radicals, such as superoxide, hydroxyl, peroxynitrite, and peroxide, cause deleterious alterations in cells including DNA fragmentation, peroxidation of cell membrane lipids, mitochondrial energy disturbances and alteration in functionality of transporter proteins, they are considered as the main culprit having the key role in pathology of neurodegenerative, ischemic, and traumatic CNS disorders (Mahadik and Mukherjee, 1996; Dugan et al., 2001).

Neuroprotective compounds based on carbon-60 fullerene the molecules having a 3-D pattern of evenly spaced carbon atoms, have been fabricated by the application of nanotechnological approach (Dugan et al., 2001). Fullerenols, hydroxyl functional group possessing fullerene derivatives, have been demonstrated to act as an antioxidant and free radical scavenger, due to which they are capable of reducing glutamate, N-methyl-d-aspartate (NMDA), Amino-3-hydroxyl-5-methyl-4-isoxazole-propionate (AMPA), and kainite induced excitotoxicity and apoptosis. The ability of these nano-structures to inhibit glutamate channels without affecting GABA (A) or taurine receptors as well as their capability to lower the glutamate-mediated intracellular calcium concentrations are the suggested mechanisms for fullerenol mediated neuroprotection (Jin et al., 2000; Dugan et al., 2001).

\section{Curcumin}

Curcumin (diferuloylmethane), a biologically active and chief phenolic constituent of turmeric obtained from the rhizomes of Curcuma longa Linn, which in its crude form has been employed as a spice, dietary supplement, and as a component of various traditional medicines, has shown tremendous therapeutic efficacy in several disease (Chattopadhyay et al., 2008). Being a natural antioxidant, curcumin has been found to possess many pharmacological activities including anti-inflammatory, antimicrobial, anticancer, the neuroprotective effect in neurodegenerative disorders (Table 5), in both preclinical and clinical studies. Furthermore, curcumin has demonstrated hepatoprotective, nephroprotective, cardioprotective, neuroprotective, hypoglycemic, antirheumatic behavior, among which its neuroprotective action against various neurodegenerative disorders has attracted the attention of researchers. Despite the wide medicinal applications of curcumin, its clinical implication is hindered due to low solubility, physico-chemical instability, poor bioavailability, rapid metabolism, and poor pharmacokinetic (Chattopadhyay et al., 2008). However, these problems can be solved by developing efficient delivery system, and the nanotechnological approach has provided a platform to handle all the hurdles for the efficient delivery and action of curcumin (Naksuriya et al., 2014).

Different types of nano-carriers such as nanoparticles, micelles, nanocrystals, nano-emulsions, and nano-liposomes 
TABLE 5 | Evaluation of targeted curcumin nanoformulations for CNS therapeutics.

\begin{tabular}{|c|c|c|c|}
\hline Nanoformulations & Target disease & Outcomes & References \\
\hline Biodegradable PLGA-curcumin & Alzheimer's Disease & $\begin{array}{l}\text { Exhibit non-toxicity in human neuroblastoma SK-N-SH } \\
\text { cells and protect from } \mathrm{H}_{2} \mathrm{O}_{2} \text { - induced rise in } \mathrm{ROS} \text {. Able } \\
\text { to prevent the induction of the } \\
\text { redox-sensitive/transcription factor Nrf2 in the presence } \\
\text { of } \mathrm{H}_{2} \mathrm{O}_{2} \text {, indicative approach to protect neurons } \\
\text { against oxidative injury that is usually observed in } \mathrm{AD}\end{array}$ & Doggui et al., 2012 \\
\hline $\begin{array}{l}\text { PEG-liposomes with the anti-transferrin, lipid } \\
\text { conjugate liposome, nanoliposomes, } \\
\text { PEG-polylactic acid block copolymer }\end{array}$ & Alzheimer's Disease & Aggregation inhibition of $A \beta$ & Mourtas et al., 2014 \\
\hline $\begin{array}{l}\text { tApoE3-conjugated and Curcumin loaded } \\
\text { PBCA polymer nanoparticles }\end{array}$ & Alzheimer's disease & Treatment of $A \beta$-induced cytotoxicity in $A D$ & Mulik et al., 2010 \\
\hline Curcumin-gold nanoparticles & Alzheimer's disease & $\begin{array}{l}\text { Interacted with amyloid protein/peptide and } \\
\text { simultaneously diminish amyloid fibrillation and dissolve } \\
\text { amyloid fibrils by acting as artificial molecular } \\
\text { chaperones }\end{array}$ & Palmal et al., 2014 \\
\hline $\begin{array}{l}\text { Anti-amyloid antibody-Conjugated and } \\
\text { curcumin/dexamethasone loaded } \\
\text { gadolinium/magnetic nanoparticles }\end{array}$ & Alzheimer's disease & $\begin{array}{l}\text { Early diagnosis, effective targeting, and as a therapeutic } \\
\text { agent(s) of cerebrovascular amyloid }\end{array}$ & Jaruszewski et al., 2014 \\
\hline $\begin{array}{l}\text { PLGA-bPEG-triphenylphosphonium polymer } \\
\text { (PLGA-b-PEG-TPP)-based curcumin } \\
\text { nanoformulation }\end{array}$ & Huntington's disease & $\begin{array}{l}\text { Confirmed significant cytosolic and mitochondrial } \\
\text { fractions in cells, indicating mitochondria-targeting } \\
\text { chemotherapeutics }\end{array}$ & Marrache and Dhar, 2012 \\
\hline Solid-lipid-based curcumin nanoformulation & Huntington's disease & $\begin{array}{l}\text { Attenuated 3-nitropropionic-acid- induced Huntington's } \\
\text { disease in rats by increasing complex II activity, } \\
\text { restoring the glutathione and superoxide dismutase }\end{array}$ & Sandhir et al., 2014 \\
\hline $\begin{array}{l}\text { Poly (N-isopropyl acrylamide)-curcumin } \\
\text { nanoformulation }\end{array}$ & Ischemic stroke & 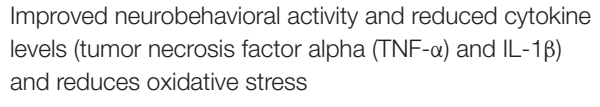 & Ahmad et al., 2016 \\
\hline Solid lipid nanoparticles of curcumin & Ischemic stroke & $\begin{array}{l}\text { Alleviated behavioral, oxidative, and nitrosative stress; } \\
\text { acetylcholinesterase; and mitochondrial enzyme } \\
\text { complex, and physiological parameters in cerebral } \\
\text { ischemic reperfusion injury in rats }\end{array}$ & Kakkar et al., 2013 \\
\hline
\end{tabular}

have fascinated the researchers in order to address problems related to poor bioavailability and pharmacokinetic of curcumin. In past few years, a lot of studies were carried out to find out the efficacy of various nanoformulations for better therapeutic activity. In a study, Joseph et al investigated the uptake and diffusion of curcumin loaded PLGA-PEG nanoparticles in neonatal rat brain. They observed neuroprotection against impaired blood-brain barrier in regions of injury. These nanoparticles diffuses effectively through the brain parenchyma (Joseph et al., 2018). In another study, Zhang et al. formulated curcumin-loaded polysorbate 80 modified cerasome (CPC) nanoparticles and delivered them to the MPTP-induced PD mice by ultrasound-targeted microbubble destruction of BBB. They reported better stability, longer circulation time, and higher permeation of nanoformulation of curcumin as compared to bulk curcumin. Furthermore, they observed improved behavior disorder along with dopamine depletion after treatment with CPC NPs (15 mg curcumin/kg) (Nisi Zhang et al., 2018). In in-vitro as well as in-vivo studies, PNPs encapsulated curcumin $\left(\right.$ NanoCurc $\left.^{\mathrm{TM}}\right)$ demonstrated better efficacy in protecting neurons from oxidative insults. NanoCurc ${ }^{\mathrm{TM}}$ treatment protected human SK-N-SH cells from $\mathrm{H}_{2} \mathrm{O}_{2}$ mediated ROS insults. In vivo, intraperitoneal (IP) injection of NanoCurc ${ }^{\mathrm{TM}}$ at a dose of $25 \mathrm{mg} / \mathrm{kg}$ twice daily in athymic mice demonstrated significant curcumin levels in the brain and resulted in decreased levels of $\mathrm{H}_{2} \mathrm{O}_{2}$, and caspases activities in brain along with increased glutathione concentrations (Ray et al., 2011). In a study, curcumin-encapsulated PLGA NPs (Cur-PLGA-NPs) demonstrated better effect on neural stem cell proliferation and neuronal differentiation in vitro as well as in vivo, as compared to bulk curcumin. Cur-PLGA-NPs significantly elevated expression of genes related to cell proliferation and neuronal differentiation in hippocampal region. They produced better effect on impaired learning and memory parameters in an $\mathrm{A} \beta$ induced rat model of AD. By in silico molecular docking studies it was found that these NPs induced neurogenesis through canonical Wnt/ $\beta$-catenin pathway (Tiwari et al., 2013). Mathew et al synthesized a water soluble PLGA coatedcurcumin NPs and coupled it with Tet-1 peptide, a peptide having high affinity to neurons. They found that curcumin encapsulated NPs successfully destroyed amyloid aggregates along with anti-oxidative property and non-cytotoxicity (Mathew et al., 2012).

\section{Growth Factors}

Various growth factors among which, Nerve growth factors (NGFs) are most essential, are needed for the development and 
TABLE 6 | A brief summary of nanoformulations related to NGF.

\begin{tabular}{|c|c|c|c|c|}
\hline Activity & Type of nanoparticle & Functional coating & Outcomes & References \\
\hline \multirow[t]{3}{*}{$\begin{array}{l}\text { Differentiation and } \\
\text { survival }\end{array}$} & Gold nanorods & $\begin{array}{l}\text { Coated with poly } \\
\text { (4-styrenesulfonic acid) } \\
\text { or } \mathrm{SiO}_{2}\end{array}$ & Increase the differentiation of NG108-15 cells & Paviolo et al., 2013 \\
\hline & Iron oxide & Conjugated to NGF & Stabilize NGF and enhance neuronal differentiation & Marcus et al., 2015 \\
\hline & Silver & & Enhance the differentiation of SH-SY5Y cells & Alon et al., 2014 \\
\hline \multirow[t]{2}{*}{$\begin{array}{l}\text { Directing Neuronal } \\
\text { migration and } \\
\text { growth }\end{array}$} & Iron oxide & & $\begin{array}{l}\text { Apply magnetic tensile forces to cause SH-SY5Y and } \\
\text { primary Schwann cell cultures to migrate toward } \\
\text { predefined directions }\end{array}$ & Riggio et al., 2012 \\
\hline & Iron oxide & Conjugated to NGF & $\begin{array}{l}\text { Apply magnetic tensile forces to induce directed neurite } \\
\text { sprout in PC12 cells }\end{array}$ & Riggio et al., 2014 \\
\hline
\end{tabular}

phenotype maintenance of neurons in the peripheral nervous system and for the functional integrity of neurons in the CNS. NGFs have great therapeutic potential for various CNS disorders (Table 6). Vascular endothelial growth factor (VEGF) was considered as a potentially useful therapeutic agent to attenuate ischemic brain injury, as it has been shown to participate in the process of post-ischemic brain repair via promoting neurogenesis and cerebral angiogenesis. Thus, effective neuroprotection and promotion of vascular regeneration in the ischemic brain have been achieved by treatment with VEGF loaded transferrinmodified liposomes (Tf-LPs). Zhao et al. (2010) achieved enhanced delivery of VEGF to the ischemic brain by encapsulated VEGF-encoding plasmids in Tf-LPs. It was found that the rats treated with Tf-LPs exhibited increased levels of VEGF mRNA and protein in the ischemic brain, compared with the rats treated with unmodified liposomes or saline.

\section{Edaravone}

Edaravone (EDR), a well-known lipophilic drug, has shown great potential as a free radical scavenger for diseases including neurodegenerative disease, cardiovascular disease, and cancer. Recently, it has fascinated researchers as and has shown noteworthy pharmacological value against the incurable diseases like ALS and AD (Cruz, 2018). No oral formulation of the EDR is currently available in the market and liquid formulation for the purpose of intravenous infusion is the only commercially available formulation. Though, oral bioavailability of EDR is very less, yet, it has shown great potential for $\mathrm{AD}$, cerebral aneurysm via oral administration in preclinical studies (Hudson et al., 2013). The EDR loaded lipid-based nanosystem (LNS) has been developed to facilitate its efficient oral delivery by augmenting the oral bioavailability. Solid-LNS showed elevated cellular uptake and better neuroprotective effect compared to EDR in SH-SY5Y695 cell line (Parikh et al., 2017).

\section{OBSTACLES TO CLINICAL TRANSLATION}

The emerging role of nanotechnology in therapeutics is not untouched by the challenges and does not always demonstrate promising results but also has been associated with several risks (Figure 6). Currently, nano-based approach is considered as a successful tool for delivery of drugs across BBB (Wong et al., 2012; Tajes et al., 2014; Havel et al., 2016). Although, a number of nanomedicine are in its infancy in the preclinical and clinical studies, and still sufficient data required to prove them as a better approach over conventional neurotherapeutics (Dinda and Pattnaik, 2013). The composition of nanocarrier is the key determinant of its properties, and may be responsible for oxidative stress, amino acid disturbance and BBB disruption that cause neurotoxicity in the brain (Sharma and Sharma, 2007). Although, nanoparticles functionalized with specific ligands provide successful drug targeting, but their extremely small size and the large surface area may cause problems like particle aggregation, interparticular friction, limited drug loading and high clearance rate sufficient to preclude their use in diagnosis and drug delivery.

The increased surface area results in an augmented chemical reactivity of the nanoparticles which then increase the production of ROS and ultimately leads to toxicity, such as neuroinflammation, excitotoxicity, DNA damage and allergic responses. Toxicity pattern of the nanocarriers depends on its state of aggregation, mechanical properties, mode of drug administration (Vega-Villa et al., 2008). Therefore, biocompatibility and biodegradability of nano-drugs are

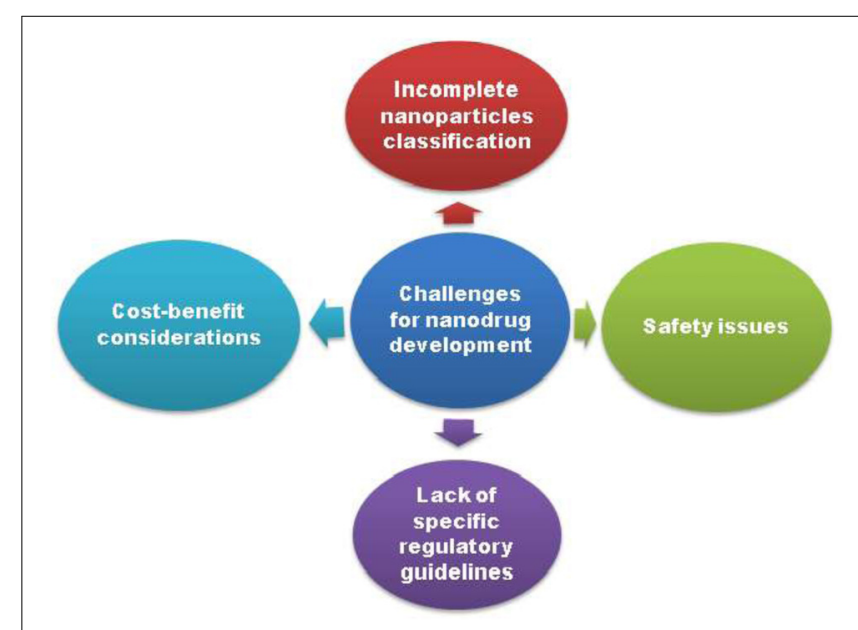

FIGURE 6 | Various challenges for the nanotechnology-based drug delivery. 
also critical to be fully understood. As nanomedicines have to interact with neurons to show their response, multidimensional interaction at neuronal level and restricted anatomical access increase the challenges in nano-based drug delivery (Jain, 2007).

The ultimate goal of nano-mediated CNS drug-delivery systems is to engineer the nanocarriers to be safe and to enable their long term use without any adverse side effects which made them successful in clinical translation from bench to bedside.

\section{FUTURE PERSPECTIVES}

Blood-brain barrier are the one of the pharmacologically active shield against CNS disorders. Brain-targeted drug delivery systems has been developed in last few recent years and gained large attention. The obstruction posed by BBB toward therapeutic drugs against diseased part of brain tissues, braintargeted drug delivery systems seems to be the most promising strategy to address our natural defense system. A clear perceptive toward the functions of brain cells such as microglia, astrocytes, endothelial cells, and neural stem cells in neurodisorders pathology is requisite in order to develop successful novel targeted-drug delivery systems. Even though, several nanoformulations have shown great efficacy in preclinical and clinical studies, their clinical translation from bench to bedside is not very successful due to inadequate information about their final fate in terms of toxicity, and other problems like aggregation and rapid clearance due to nano-size. Indepth and complete toxicological studies of brain targeting nanoformulations with their clear mechanism of action and pharmacokinetics with and without therapeutics should be essentially investigated. Besides this, more research has to be done in order to determine the fate of nanocarriers inside body, their systemic toxicity, biocompatibility, and RES elimination. The therapeutic potential of nanomedicine will rely on the rational approach and further designing of nanomaterials based on detailed and comprehensive knowledge of obtained from biological processes. Several basic concerns should be addressed in the future to achieve the successful clinical translation of nanoformulations:

(i) The nanomaterials should be biodegradable in nature and provide effective and safe brain-targeted drug delivery systems.

(ii) An eco-friendly green approach should be developed for preparation of nanoformulations.

(iii) The factors like shape, size, charge and moiety attached to nanomaterials should be well elucidated and evaluated, which is essential for crossing and developing braintargeted drug delivery systems.

(iv) A non- invasive alternative method for nanocarrier drug delivery should be developed in order to avoid complications such as poor patient compliance associated with i.v., and other invasive routes. Newer drug-administration routes for nanocarrier-mediated
CNS drug-delivery systems such as oral, transbuccal, mucosal/sublingual, or nasal, need to be explored.

The main issue for bench to bedside translation of nanoformulations is toxicity which has to be dealt carefully. The fate and mechanism of nanocarriers with respect to their bulk counterparts should be studied in detail before it comes to market. Therefore, in near future, fundamental research has to be carried out to deal with these issues if the successful efficient application of nanoformulations has to be achieved.

\section{CONCLUSION}

Central nervous system diseases, such as $\mathrm{AD}, \mathrm{PD}$, stroke, brain tumors, and neuroinflammation have become distressful devastating to mankind due to the change in lifestyle and the rapid continued deterioration of the environment. BBB and BCSFB is the main physiological barrier which possess big bottleneck for the successful treatment of CNS disorders and brain tumors, complex anatomical structure, unique microenvironment, and their selectivity toward any foreign compound including drug is treated as a biggest challenge toward CNS drug delivery. High therapeutic drug concentration inside brain should be reached through effective and safe carrier, hence there is a need of developing good cargo, which carries drug to CNS in effective concentration without causing systemic side effects.

Nanomedicines have been implicated to address the problems related to treatment of neurological disorder and have a cutting edge over the conventional CNS therapy. Nanocarriers such as nanoparticles, liposomes, nanopharmaceuticals, nanotubes, nanoemulsions, nanosensors, dendrimers, and micelles, etc. are having high prospective in neuroprotection as theranostics. Engineered nanomaterials are designed by scientistist in order to increase its biocompatibility, blood circulation time and reduced their systemic toxicity, prevent the drug from degradation from physiological environment with sustained and controlled release along with the site-specific targeting. The current demand for the successful nano-based approaches focused on the regeneration and neuroprotection that will significantly benefit from continued nano based approach along with the advancement in neuronal cell biology their pathology and physiology. In models of $\mathrm{AD}, \mathrm{PD}$ and stroke, different nanoscalic approaches have been identified to cure neurological disorders such as inhibition of $A \beta$ oligomerization, reduce reactive oxygen species, and enhance functional neuronal networks. Nanocarriers have enabled targeted delivery of chemotherapeutics as well as antisense gene therapy, in malignant brain tumors, ensuing in remarkable inhibition of disease progression in vitro as well as in vivo study. Fortunately, a small number of these promising preclinical studies have been successfully translated to the clinic for effective patient care. Nanotechnology has been implicated in the development of nanoformulations of various neuroprotective drugs such as curcumin, nerve growth factors, and edaravone, etc. but still limited data are provided related to their adverse effects. Future perspective of use of nanotechnology in CNS drug delivery 
is very promising and it opens new avenues in the treatment of neurological disorders as it has the potential to fundamentally revolutionize the way we approach CNS-targeted therapeutics due to their ability to nanoengineered the drug/carriers to cross $\mathrm{BBB}$, diffuse within the brain tissue, target specific cell, or signaling systems for delivering therapeutics.

\section{AUTHOR CONTRIBUTIONS}

AP wrote the initial first draft. SN conceptualized, proofread, edited, and wrote the first draft. SN and SF completed

\section{REFERENCES}

Aebischer, P., Schluep, M., Déglon, N., Joseph, J.-M., Hirt, L., Heyd, B., et al. (1996). Intrathecal delivery of cntf using encapsulated genetically modifiedxenogeneic cells in amyotrophic lateral sclerosis patients. Nat. Med. 2:696. doi: 10.1038/ nm0696-696

Ahmad, N., Ahmad, I., Umar, S., Iqbal, Z., Samim, M., and Ahmad, F. J. (2016). Pnipam nanoparticles for targeted and enhanced nose-to-brain delivery of curcuminoids: Uplc/esi-q-tof-ms/ms-based pharmacokinetics and pharmacodynamic evaluation in cerebral ischemia model. Drug Deliv. 23, 2095-2114. doi: 10.3109/10717544.2014.941076

Alexander, A., Agrawal, M., Uddin, A., Siddique, S., Shehata, A. M., Shaker, M. A., et al. (2019). Recent expansions of novel strategies towards the drug targeting into the brain. Int. J. Nanomed. 14, 5895-5909. doi: 10.2147/IJN.S210876

Ali, A., Pillai, K. K., Ahmad, F. J., Dua, Y., Khan, Z. I., and Vohora, D. (2007). Comparative efficacy of liposome-entrapped amiloride and free amiloride in animal models of seizures and serum potassium in mice. Eur. Neuropsychopharm. 17, 227-229. doi: 10.1016/j.euroneuro.2006.05.003

Aliabadi, H. M., and Lavasanifar, A. (2006). Polymeric micelles for drug delivery. Expert Opin. Drug Deliv. 3, 139-162. doi: 10.1517/17425247.3.1.139

Alon, N., Miroshnikov, Y., Perkas, N., Nissan, I., Gedanken, A., and Shefi, O. (2014). Substrates coated with silver nanoparticles as a neuronal regenerative material. Int. J Nanomed. 9:23. doi: 10.2147/IJN.S45639

Alyautdin, R., Khalin, I., Nafeeza, M. I., Haron, M. H., and Kuznetsov, D. (2014). Nanoscale drug delivery systems and the blood-brain barrier. Int. J. Nanomed. 9, 795-811. doi: 10.2147/IJN.S52236

Aso, E., Martinsson, I., Appelhans, D., Effenberg, C., Benseny-Cases, N., and Cladera, J. (2019). Poly(propylene imine) dendrimers with histidine-maltose shell as novel type of nanoparticles for synapse and memory protection. Namomed. Nanotechnol. 17, 198-209. doi: 10.1016/j.nano.2019.01.010

Asthana, A., Chauhan, A. S., Diwan, P. V., and Jain, N. K. (2005). Poly(amidoamine) (PAMAM) dendritic nanostructures for controlled sitespecific delivery of acidic anti-inflammatory active ingredient. AAPS Pharm. Sci. Tech. 6, E536-E542. doi: 10.1208/pt060367

Barchet, T. M., and Amiji, M. M. (2009). Challenges and opportunities in cns delivery of therapeutics for neurodegenerative diseases. Expert Opin. Drug Deliv. 6, 211-225. doi: 10.1517/17425240902758188

Barenholz, Y. (2012). Doxil ${ }^{\circledR}$ - the first FDA-approved nano-drug: lessons learned. J. Control Rel. 160, 117-134. doi: 10.1016/j.jconrel.2012.03.020

Bates, G. P., Dorsey, R., Gusella, J. F., Hayden, M. R., Kay, C., Leavitt, B. R., et al. (2015). Huntington disease. Nat. Rev. Dis. Primers 1:15005. doi: 10.1038/nrdp. 2015.5

Batrakova, E. V., and Kabanov, A. V. (2008). Pluronic block copolymers: evolution of drug delivery concept from inert nanocarriers to biological response modifiers. J. Control Rel. 130, 98-106. doi: 10.1016/j.jconrel.2008. 04.013

Bawarski, W. E., Chidlowsky, E., Bharali, D. J., and Mousa, S. A. (2008). Emerging nanopharmaceuticals. Nanomedicine 4, 273-282. doi: 10.1016/j.nano.2008.06. 002

Bennewitz, M. F., and Saltzman, W. M. (2009). Nanotechnology for delivery of drugs to the brain for epilepsy. Neurotherapeutics 6, 323-336. doi: 10.1016/j. nurt.2009.01.018 the final draft. NIPER-R communication no. is: NIPERR/Communication/127.

\section{FUNDING}

This work was supported by Department of Pharmaceuticals, Ministry of Chemical and Fertilizer, Government of India. SN was further supported by Women Scientist Scheme (WOS-A), Department of Science and Technology, Government of India (grant number SR/WOS-A/LS-1224/2015). AP was also supported by GPAT, AICTE scholarship.

Bidros, D. S., and Vogelbaum, M. A. (2009). Novel drug delivery strategies in neuro-oncology. Neurotherapeutics 6, 539-546. doi: 10.1016/j.nurt.2009.04.004

Blasi, P., Giovagnoli, S., Schoubben, A., Ricci, M., and Rossi, C. (2007). Solid lipid nanoparticles for targeted brain drug delivery. Adv. Drug Deliv. Rev. 59, 454-477. doi: 10.1016/j.addr.2007.04.011

Bobo, D., Robinson, K. J., Islam, J., Thurecht, K. J., and Corrie, S. R. (2016). Nanoparticle-based medicines: a review of FDA-approved materials and clinical trials to date. Pharm. Res. 33, 2373-2387. doi: 10.1007/s11095-016-1958

Bondì, M. L., Craparo, E. F., Giammona, G., and Drago, F. (2010). Brain-targeted solid lipid nanoparticles containing riluzole: preparation, characterization and biodistribution. Nanomedicine 5, 25-32. doi: 10.2217/nnm.09.67

Bonferoni, M. C., Rossi, S., Sandri, G., Ferrari, F., Gavini, E., Rassu, G., et al. (2019). Nanoemulsions for “Nose-to-Brain" drug delivery. Pharmaceutics 11:84. doi: 10.3390/pharmaceutics11020084

Bradford, J., Shin, J.-Y., Roberts, M., Wang, C.-E., Li, X.-J., and Li, S. (2009). Expression of mutant huntingtin in mouse brain astrocytes causes agedependent neurological symptoms. Proc. Natl. Acad. Sci. U.S.A. 106, 2248022485. doi: 10.1073/pnas.0911503106

Brigger, I., Morizet, J., Aubert, G., Chacun, H., Terrier-Lacombe, M.-J., Couvreur, P., et al. (2002). Poly (ethylene glycol)-coated hexadecylcyanoacrylate nanospheres display a combined effect for brain tumor targeting. J. Pharmacol. Exp. Ther. 303, 928-936. doi: 10.1124/jpet.102.039669

Caster, J. M., Patel, A. N., Zhang, T., and Wang, A. (2017). Investigational nanomedicines in 2016: a review of nanotherapeutics currently undergoing clinical trials. Wiley Interdiscip. Rev. Nanomed. Nanobiotechnol. 9:e1416. doi: 10.1002/wnan.1416

Cayero-Otero, M. D., Gomes, M. J., Martins, C., Álvarez-Fuentes, J., FernándezArévalo, M., Sarmento, B., et al. (2019). In vivo biodistribution of venlafaxinePLGA nanoparticles for brain delivery: plain vs. functionalized nanoparticles. Expert Opin. Drug Deliv. 12, 1413-1427. doi: 10.1080/17425247.2019.1690452

Centerwatch (2017). FDA Approved Drugs. Available online at: www.centerwatch.com/drug-information/fda- approved-drugs (accessed October 25, 2017).

Chakraborty, S., Dhakshinamurthy, G. S., and Misra, S. K. (2017). Tailoring of physicochemical properties of nanocarriers for effective anti-cancer applications. J. Biomed. Mater. Res. A 105, 2906-2928. doi: 10.1002/jbm.a.36141

Chan, H. K., and Kwok, P. C. (2011). Production methods for nanodrug particles using the bottom-up approach. Adv. Drug Deliv. Rev. 63, 406-416. doi: 10.1016/ j.addr.2011.03.011

Chattopadhyay, N., Zastre, J., Wong, H.-L., Wu, X. Y., and Bendayan, R. (2008). Solid lipid nanoparticles enhance the delivery of the hiv protease inhibitor, atazanavir, by a human brain endothelial cell line. Pharm. Res. 25, 2262-2271. doi: 10.1007/s11095-008-9615-9612

Chaturvedi, K., Ganguly, K., Nadagouda, M. N., and Aminabhavi, T. M. (2013). Polymeric hydrogels for oral insulin delivery. J. Control Rel. 165, 129-138. doi: 10.1016/j.jconrel.2012.11.005

Chen, C., Mei, H., Shi, W., Deng, J., Zhang, B., Guo, T., et al. (2013). Egfpegfl-conjugated plga nanoparticles for targeted delivery of sirna into injured brain microvascular endothelial cells for efficient rna interference. PLoS One 8:e60860. doi: 10.1371/journal.pone.0060860

Chen, T., Li, C., Li, Y., Yi, X., Wang, R., Lee, S. M., et al. (2017). Small-sized mPEGPLGA nanoparticles of schisantherin A with sustained release for enhanced 
brain uptake and anti-Parkinsonian activity. ACS Appl. Mater. Interf. 9, 95169527. doi: 10.1021/acsami.7b01171

Corace, G., Angeloni, C., Malaguti, M., Hrelia, S., Stein, P. C., Brandl, M., et al. (2014). Multifunctional liposomes for nasal delivery of the anti-alzheimer drug tacrine hydrochloride. J. Liposome Res. 24, 323-335. doi: 10.3109/08982104. 2014.899369

Cruz, M. P. (2018). Edaravone (Radicava): a novel neuroprotective agent for the treatment of amyotrophic lateral sclerosis. $P$ T 43, 25-28.

Cui, Z., Lockman, P. R., Atwood, C. S., Hsu, C.-H., Gupte, A., Allen, D. D., et al. (2005). Novel d-penicillamine carrying nanoparticles for metal chelation therapy in alzheimer's and other cns diseases. Eur. J. Pharm. Biopharm. 59, 263-272. doi: 10.1016/j.ejpb.2004.07.009

Das, D., and Lin, S. (2005). Double-coated poly (butylcynanoacrylate) nanoparticulate delivery systems for brain targeting of dalargin via oral administration. J. Pharm. Sci. 94, 1343-1353. doi: 10.1002/jps.20357

Dhanikula, R. S., Argaw, A., Bouchard, J.-F., and Hildgen, P. (2008). Methotrexate loaded polyether-copolyester dendrimers for the treatment of gliomas: enhanced efficacy and intratumoral transport capability. Mol. Pharm. 5, 105116. doi: $10.1021 / \mathrm{mp} 700086 \mathrm{j}$

Dhawan, S., Kapil, R., and Singh, B. (2011). Formulation development and systematic optimization of solid lipid nanoparticles of quercetin for improved brain delivery. J. Pharm. Pharmacol. 63, 342-351. doi: 10.1111/j.2042-7158. 2010.01225.x

Dias, A. P., Santos, S. S. D., Silva, J. V. D., Filho, R. P., Ferreira, E. I, Seoud, O. E., et al. (2020). Dendrimers in the context of nanomedicine. Int. J. Pharm. 573:118814. doi: 10.1016/j.ijpharm.2019.118814

Dinda, C. S., and Pattnaik, G. (2013). Nanobiotechnology-based drug delivery in brain targeting. Curr. Pharm. Biotechnol. 14, 1264-1274. doi: 10.2174/ 1389201015666140608143719

Doggui, S., Sahni, J. K., Arseneault, M., Dao, L., and Ramassamy, C. (2012). Neuronal uptake and neuroprotective effect of curcumin-loaded plga nanoparticles on the human SK-N-SH cell line. J. Alzheimer Dis. 30, 377-392. doi: 10.3233/JAD-2012-112141

Dugan, L., Lovett, E., Quick, K., Lotharius, J., Lin, T., and O'malley, K. (2001). Fullerene-based antioxidants and neurodegenerative disorders. Parkinsonism. Relat. Disord. 7, 243-246. doi: 10.1016/s1353-8020(00) 00064-X

Duncan, R., and Izzo, L. (2005). Dendrimer biocompatibility and toxicity. Adv. Drug Deliv Rev. 57, 2215-2237. doi: 10.1016/j.addr.2005.09.019

Estevez, A., Pritchard, S., Harper, K., Aston, J., Lynch, A., Lucky, J., et al. (2011). Neuroprotective mechanisms of cerium oxide nanoparticles in a mouse hippocampal brain slice model of ischemia. Free Radic Biol. Med. 51, 11551163. doi: 10.1016/j.freeradbiomed.2011.06.006

Feigin, V. L., Nichols, E., Alam, T., Bannick, M. S., Beghi, E., et al. (2019). GBD. 2016 Neurology Collaborators. . Global, regional, and national burden of neurological disorders, 1990-2016: a systematic analysis for the Global Burden of Disease Study 2016. Lancet Neurol. 18, 459-480. doi: 10.1016/S14744422(18)30499-X

Feldman, E. J., Kolitz, J. E., Trang, J. M., Liboiron, B. D., Swenson, C. E., Chiarella, M. T., et al. (2012). Pharmacokinetics of CPX-351; a nano-scale liposomal fixed molar ratio formulation of cytarabine: daunorubicin, in patients with advanced leukemia. Leuk. Res. 36, 1283-1289. doi: 10.1016/j.leukres.2012.07.006

Fetterly, G. J., and Straubinger, R. M. (2003). Pharmacokinetics of paclitaxelcontaining liposomes in rats. AAPS Pharm. Sci. 5:E32. doi: 10.1208/ps050432

Fischer, H., Gottschlich, R., and Seelig, A. (1998). Blood-brain barrier permeation: molecular parameters governing passive diffusion. J. Membrane Biol. 165, 201-211. doi: 10.1007/s002329900434

Flexion Therapeutics Inc (2017). Our Product: Zilretta (triamcinolone acetonide extended. (release)Formulation). Available online at: https://flexiontherapeutics. com/our-product (accessed October 25, 2017).

Food and Drug Administration (2017). Novel drug approvals for 2017. Available online at: www.fda.gov/drugs/developmentapprovalprocess druginnovation/ucm537040 (accessed October 25, 2017).

Fukuta, T., Ishii, T., Asai, T., Sato, A., Kikuchi, T., Shimizu, K., et al. (2015). Treatment of stroke with liposomal neuroprotective agents under cerebral ischemia conditions. Eur. J. Pharm. Biopharm. 97, 1-7. doi: 10.1016/j.ejpb.2015. 09.020
Gao, H., Pang, Z., and Jiang, X. (2013). Targeted delivery of nano-therapeutics for major disorders of the central nervous system. Pharm. Res. 30, 2485-2498. doi: $10.1007 /$ s11095-013-1122-1124

Gao, K., and Jiang, X. (2006). Influence of particle size on transport of methotrexate across blood brain barrier by polysorbate 80 -coated polybutylcyanoacrylate nanoparticles. Int. J. Pharm. 310, 213-219. doi: 10.1016/j.ijpharm.2005.11.040

Gao, L., Liu, G., Ma, J., Wang, X., Zhou, L., and Li, X. (2012). Drug nanocrystals: in vivo performances. J. Control Rel. 160, 418-430. doi: 10.1016/j.jconrel.2012. 03.013

Garcion, E., Lamprecht, A., Heurtault, B., Paillard, A., Aubert-Pouessel, A., Denizot, B., et al. (2006). A new generation of anticancer, drug-loaded, colloidal vectors reverses multidrug resistance in glioma and reduces tumor progression in rats. Mol. Cancer Ther. 5, 1710-1722. doi: 10.1158/1535-7163.MCT-06-0289

Georganopoulou, D. G., Chang, L., Nam, J.-M., Thaxton, C. S., Mufson, E. J., Klein, W. L., et al. (2005). Nanoparticle-based detection in cerebral spinal fluid of a soluble pathogenic biomarker for alzheimer's disease. Proc. Natl. Acad. Sci. U.S.A. 102, 2273-2276. doi: 10.1073/pnas.0409336102

Georgieva, J., Hoekstra, D., and Zuhorn, I. (2014). Smuggling drugs into the brain: an overview of ligands targeting transcytosis for drug delivery across the bloodbrain barrier. Pharmaceutics 6, 557-583. doi: 10.3390/pharmaceutics6040557

Gloor, S. M., Wachtel, M., Bolliger, M. F., Ishihara, H., Landmann, R., and Frei, K. (2001). Molecular and cellular permeability control at the blood-brain barrier. Brain Res. Brain Res. Rev. 36, 258-264. doi: 10.1016/s0165-0173(01)00102-103

Godinho, B. M., Ogier, J. R., Darcy, R., O'driscoll, C. M., and Cryan, J. F. (2013). Self-assembling modified $\beta$-cyclodextrin nanoparticles as neuronal sirna delivery vectors: focus on huntington's disease. Mol. Pharm. 10, 640-649. doi: $10.1021 / \mathrm{mp} 3003946$

Guo, L., Ren, J., and Jiang, X. (2012). Perspectives on brain-targeting drug delivery systems. Curr. Pharm. Biotechnol. 13, 2310-2318. doi: 10.2174/ 138920112803341770

Hanafy, A., Spahn-Langguth, H., Vergnault, G., Grenier, P., Grozdanis, T. M., Lenhardt, T., et al. (2007). Pharmacokinetic evaluation of oral fenofibrate nanosuspensions and SLN in comparison to conventional suspensions of micronized drug. Adv. Drug Deliv. Rev. 59, 419-426. doi: 10.1016/j.addr.2007. 04.005

Havel, H., Finch, G., Strode, P., Wolfgang, M., Zale, S., and Bobe, I. (2016). Nanomedicines: from bench to bedside and beyond. AAPS J. 18, 1373-1378. doi: 10.1208/s12248-016-9961-7

He, H., Li, Y., Jia, X.-R., Du, J., Ying, X., Lu, W.-L., et al. (2011). Pegylated poly (amidoamine) dendrimer-based dual-targeting carrier for treating brain tumors. Biomaterials 32, 478-487. doi: 10.1016/j.biomaterials.2010.09.002

Hernández-Pedro, N. Y., Rangel-López, E., Magaña-Maldonado, R., De La Cruz, V. P., Santamaría Del Angel, A., Pineda, B., et al. (2013). Application of nanoparticles on diagnosis and therapy in gliomas. Biomed. Res. 2013:351031. doi: $10.1155 / 2013 / 351031$

Honda, M., Asai, T., Oku, N., Araki, Y., Tanaka, M., and Ebihara, N. (2013). Liposomes and nanotechnology in drug development: focus on ocular targets. Int. J. Nanomed. 8, 495-503. doi: 10.2147/IJN.S30725

Hrkach, J., Von Hoff, D., Ali, M. M., Andrianova, E., Auer, J., Campbell, T., et al. (2012). Preclinical development and clinical translation of a PSMA-targeted docetaxel nanoparticle with a differentiated pharmacological profile. Sci. Transl. Med. 4:128ra39. doi: 10.1126/scitranslmed.3003651

Hsiao, M.-H., Larsson, M., Larsson, A., Evenbratt, H., Chen, Y.-Y., Chen, Y.Y., et al. (2012). Design and characterization of a novel amphiphilic chitosan nanocapsule-based thermo-gelling biogel with sustained in vivo release of the hydrophilic anti-epilepsy drug ethosuximide. J. Control. Release 161, 942-948. doi: 10.1016/j.jconrel.2012.05.038

Huang, Y. J., Wu, H. C., Tai, N. H., and Wang, T. W. (2012). Carbon nanotube rope with electrical stimulation promotes the differentiation and maturity of neural stem cells. Small 8, 2869-2877. doi: 10.1002/smll.201200715

Hudson, J. S., Hoyne, D. S., and Hasan, D. M. (2013). Inflammation and human cerebral aneurysms: current and future treatment prospects. Future Neurol. 8 , 663-676. doi: 10.2217/fnl.13.40

Jabir, N. R., Tabrez, S., Firoz, C. K., Zaidi, S. K., Baeesa, S. S., Gan, S. H., et al. (2015). A synopsis of nano-technological approaches toward anti-epilepsy therapy: present and future research implications. Curr. Drug Metab. 16, 336-345. doi: $10.2174 / 1389200215666141125142605$ 
Jain, K. (2007). Nanobiotechnology-based drug delivery to the central nervous system. Neurodegen. Dis. 4, 287-291. doi: 10.1159/000101884

Jaruszewski, K. M., Curran, G. L., Swaminathan, S. K., Rosenberg, J. T., Grant, S. C., Ramakrishnan, S., et al. (2014). Multimodal nanoprobes to target cerebrovascular amyloid in alzheimer's disease brain. Biomaterials 35, 19671976. doi: 10.1016/j.biomaterials.2013.10.075

Jia, L., Wong, H., Wang, Y., Garza, M., and Weitman, S. D. (2003). Carbendazim: disposition, cellular permeability, metabolite identification, and pharmacokinetic comparison with its nanoparticle. J. Pharm. Sci. 92, 161-172. doi: $10.1002 /$ jps. 10272

Jin, H., Chen, W., Tang, X., Chiang, L., Yang, C., Schloss, J., et al. (2000). Polyhydroxylated c60, fullerenols, as glutamate receptor antagonists and neuroprotective agents. J. Neurosci. Res. 62, 600-607. doi: 10.1002/10974547(20001115)62:4\&lt;600::AID-JNR15\&gt;3.0.CO;2-F

Jinno, J., Kamada, N., Miyake, M., Yamada, K., Mukai, T., Odomi, M., et al. (2006). Effect of particle size reduction on dissolution and oral absorption of a poorly water-soluble drug, cilostazol, in beagle dogs. J. Control Rel. 111, 56-64. doi: 10.1016/j.jconrel.2005.11.013

Joachim, E., Kim, I.-D., Jin, Y., Kim, K. K., Lee, J.-K., and Choi, H. (2014). Gelatin nanoparticles enhance the neuroprotective effects of intranasally administered osteopontin in rat ischemic stroke model. Drug Deliv. Transl. Res. 4, 395-399. doi: 10.1007/s13346-014-0208-209

Jones, C. A., Pohar, S. L., Warren, S., Turpin, K. V., and Warren, K. G. (2008). The burden of multiple sclerosis: a community health survey. Health Qual. Life Outcomes 6:1. doi: 10.1186/1477-7525-6-1

Joseph, A., Wood, T., Chen, C.-C., Corry, K., Snyder, J. M., Juul, S. E., et al. (2018). Curcumin-loaded polymeric nanoparticles for neuroprotection in neonatal rats with hypoxic-ischemic encephalopathy. Nano Res. 11, 5670-5688. doi: 10.1007/ s12274-018-2104-y

Kabanov, A. V., Chekhonin, V., Alakhov, V. Y., Batrakova, E., Lebedev, A., MelikNubarov, N., et al. (1989). The neuroleptic activity of haloperidol increases after its solubilization in surfactant micelles. FEBS Lett. 258, 343-345. doi: 10.1016/0014-5793(89)81689-81688

Kakkar, V., Muppu, S. K., Chopra, K., and Kaur, I. P. (2013). Curcumin loaded solid lipid nanoparticles: an efficient formulation approach for cerebral ischemic reperfusion injury in rats. Eur. J. Pharm. Biopharm. 85, 339-345. doi: 10.1016/j. ejpb.2013.02.005

Kalia, L. V., and Lang, A. E. (2015). Parkinson's disease. Lancet 386, 896-912. doi: 10.1016/s0140-6736(14)61393-61393

Kaminskas, L. M., Kelly, B. D., McLeod, V. M., Sberna, G., Boyd, B. J., Owen, D. J., et al. (2011). Capping methotrexate $\alpha$-carboxyl groups enhances systemic exposure and retains the cytotoxicity of drug conjugated PEGylated polylysine dendrimers. Mol. Pharm. 8, 338-349. doi: 10.1021/mp1001872

Kaminskas, L. M., McLeod, V. M., Kelly, B. D., Sberna, G., Boyd, B. J., Williamson, M., et al. (2012). A comparison of changes to doxorubicin pharmacokinetics, antitumor activity, and toxicity mediated by PEGylated dendrimer and PEGylated liposome drug delivery systems. Nanomedicine 8, 103-111. doi: 10. 1016/j.nano.2011.05.013

Kasamatsu, H., and Nakanishi, A. (1998). How do animal DNA viruses get to the nucleus? Annu. Rev. Microbiol. 52, 627-686. doi: 10.1146/annurev.micro.52.1. 627

Kato, K., Chin, K., Yoshikawa, T., Yamaguchi, K., Tsuji, Y., Esaki, T., et al. (2012). Phase II study of NK105, a paclitaxel-incorporating micellar nanoparticle, for previously treated advanced or recurrent gastric cancer. Invest. New Drugs 30 , 1621-1627. doi: 10.1007/s10637-011-9709-2

Kaur, I. P., Bhandari, R., Bhandari, S., and Kakkar, V. (2008). Potential of solid lipid nanoparticles in brain targeting. J. Control Rel. 127, 97-109. doi: 10.1016/ j.jconrel.2007.12.018

Kawabata, Y., Yamamoto, K., Debari, K., Onoue, S., and Yamada, S. (2010). Novel crystalline solid dispersion of tranilast with high photostability and improved oral bioavailability. Eur. J. Pharm. Sci. 39, 256-262. doi: 10.1016/j.ejps.2009.12. 009

Kawakami, S., Yamamura, K., Mukai, T., Nishida, K., Nakamura, J., Sakaeda, T., et al. (2001). Sustained ocular delivery of tilisolol to rabbits after topical administration or intravitreal injection of lipophilic prodrug incorporated in liposomes. J. Pharm. Pharmacol. 53, 1157-1161. doi: $10.1211 / 0022357011776423$
Khare, M., Singh, A., and Zamboni, P. (2014). Prospect of brain machine interface in motor disabilities: the future support for multiple sclerosis patient to improve quality of life. Ann. Med. Health Sci. Res. 4, 305-312. doi: 10.4103/2141-9248. 133447

Kim, G. H., Kim, J. E., Rhie, S. J., and Yoon, S. (2015). The role of oxidative stress in neurodegenerative diseases. Exp. Neurobiol. 24, 325-340. doi: 10.5607/en.2015. 24.4.325

Kim, H. R., Andrieux, K., Delomenie, C., Chacun, H., Appel, M., Desmaële, D., et al. (2007). Analysis of plasma protein adsorption onto PEGylated nanoparticles by complementary methods: 2 -DE, CE and protein Lab-onchipVR system. Electrophoresis 28, 2252-2261. doi: 10.1002/elps.200600694

Kohane, D. S., Holmes, G. L., Chau, Y., Zurakowski, D., Langer, R., and Cha, B. H. (2002). Effectiveness of muscimol-containing microparticles against pilocarpine-induced focal seizures. Epilepsia 43, 1462-1468. doi: 10.1046/j. 1528-1157.2002.11202.x

Kou, L., Sun, J., Zhai, Y., and He, Z. (2013). The endocytosis and intracellular fate of nanomedicines: implication for rational design. Asian J. Pharm. Sci. 8, 1-10.

Kreuter, J. (2001). Nanoparticulate systems for brain delivery of drugs. Adv. Drug Deliv. Rev. 47, 65-81. doi: 10.1016/s0169-409x(00)00122-8

Kreuter, J. (2013). Mechanism of polymeric nanoparticle-based drug transport across the blood-brain barrier (bbb). J. Microencapsul. 30, 49-54. doi: 10.3109/ 02652048.2012 .692491

Kreuter, J., Shamenkov, D., Petrov, V., Ramge, P., Cychutek, K., Koch-Brandt, C., et al. (2002). Apolipoprotein-mediated transport of nanoparticle-bound drugs across the blood-brain barrier. J. Drug Targt. 10, 317-325. doi: 10.1080/ 10611860290031877

Kumar, A., and Singh, A. (2015). A review on alzheimer's disease pathophysiology and its management: an update. Pharmacol. Rep. 67, 195-203. doi: 10.1016/j. pharep.2014.09.004

Kumari, A., Yadav, S. K., and Yadav, S. C. (2010). Biodegradable polymeric nanoparticles based drug delivery systems. Colloids Surf. B Biointerf. 75, 1-18. doi: 10.1016/j.colsurfb.2009.09.001

Kurakhmaeva, K. B., Djindjikhashvili, I. A., Petrov, V. E., Balabanyan, V. U., Voronina, T. A., Trofimov, S. S., et al. (2009). Brain targeting of nerve growth factor using poly (butyl cyanoacrylate) nanoparticles. J. Drug Target 17, 564574. doi: $10.1080 / 10611860903112842$

Kurmi, B. D., Gajbhiye, V., Kayat, J., and Jain, N. K. (2011). Lactoferrin-conjugated dendritic nanoconstructs for lung targeting of methotrexate. J. Pharm. Sci. 100, 2311-2320. doi: 10.1002/jps.22469

Lamprecht, A., and Benoit, J.-P. (2006). Etoposide nanocarriers suppress glioma cell growth by intracellular drug delivery and simultaneous p-glycoprotein inhibition. J. Control Rel. 112, 208-213. doi: 10.1016/j.jconrel.2006. 02.014

Laquintana, V., Trapani, A., Denora, N., Wang, F., Gallo, J. M., and Trapani, G. (2009). New strategies to deliver anticancer drugs to brain tumors. Exp. Opin. Drug Deliv. 6, 1017-1032. doi: 10.1517/17425240903167942

Larsen, A. T., Ohlsson, A. G., Polentarutti, B., Barker, R. A., Phillips, A. R., AbuRmaileh, R., et al. (2013). Oral bioavailability of cinnarizine in dogs: relation to SNEDDS droplet size, drug solubility and in vitro precipitation. Eur. J. Pharm. Sci. 48, 339-350. doi: 10.1016/j.ejps.2012.11.004

Leiro, V., Duque Santos, S., Lopes, C. D., and Paula Pêgo, A. (2018). Dendrimers as powerful building blocks in central nervous system disease: headed for successful nanomedicine. Adv. Funct. Mater. 28:1700313. doi: 10.1002/adfm. 201700313

Li, M., Deng, H., Peng, H., and Wang, Q. (2014). Functional nanoparticles in targeting glioma diagnosis and therapies. J. Nanosci. Nanotechno. 14, 415-432. doi: $10.1166 /$ jnn.2014.8757

Li, X., Tsibouklis, J., Weng, T., Zhang, B., Yin, G., Feng, G., et al. (2017). Nano carriers for drug transport across the blood-brain barrier. J. Drug Target 25, 17-28. doi: 10.1080/1061186X.2016.1184272

Lien, C. F., Molnar, E., Toman, P., Tsibouklis, J., Pilkington, G. J., Górecki, D. C., et al. (2012). In vitro assessment of alkylglyceryl-functionalized chitosan nanoparticles as permeating vectors for the blood-brain barrier. Biomacromolecules 13, 1067-1073. doi: 10.1021/bm201790s

Liu, Z., Zhou, T., Ziegler, A. C., Dimitrion, P., and Zuo, L. (2017). Oxidative stress in neurodegenerative diseases: from molecular mechanisms to clinical applications. Oxid Med. Cell Longev. 2017:2525967. doi: 10.1155/2017/2525967 
Lovell, M., Robertson, J., Teesdale, W., Campbell, J., and Markesbery, W. (1998). Copper, iron and zinc in alzheimer's disease senile plaques. J. Neurol Sci. 158, 47-52. doi: 10.1016/s0022-510x(98)00092-96

Lovelyn, C., and Attama, A. A. (2011). Current state of nanoemulsions in drug delivery. J. Biomater. Nanobiotechnol. 2:626. doi: 10.4236/jbnb.2011. 225075

Mahadik, S. P., and Mukherjee, S. (1996). Free radical pathology and antioxidant defense in schizophrenia: a review. Schizophrenia Res. 19, 1-17. doi: 10.1016/ 0920-9964(95)00049-6

Manjunath, K., and Venkateswarlu, V. (2005). Pharmacokinetics, tissue distribution and bioavailability of clozapine solid lipid nanoparticles after intravenous and intraduodenal administration. J. Control Rel. 107, 215-228. doi: 10.1016/j.jconrel.2005.06.006

Manjunath, K., and Venkateswarlu, V. (2006). Pharmacokinetics, tissue distribution and bioavailability of nitrendipine solid lipid nanoparticles after intravenous and intraduodenal administration. J. Drug Target. 14, 632-645. doi: 10.1080/10611860600888850

Marcus, M., Skaat, H., Alon, N., Margel, S., and Shefi, O. (2015). Ngf-conjugated iron oxide nanoparticles promote differentiation and outgrowth of pc12 cells. Nanoscale 7, 1058-1066. doi: 10.1039/c4nr05193a

Markoutsa, E., Pampalakis, G., Niarakis, A., Romero, I. A., Weksler, B., Couraud, P. O., et al. (2011). Uptake and permeability studies of BBB-targeting immunoliposomes using the hCMEC/D3 cell line. Eur. J. Pharm. Biopharm. 77, 265-274. doi: 10.1016/j.ejpb.2010.11.015

Marrache, S., and Dhar, S. (2012). Engineering of blended nanoparticle platform for delivery of mitochondria-acting therapeutics. Proc. Natl. Acad. Sci. U.S.A. 109, 16288-16293. doi: 10.1073/pnas. 1210096109

Martins, S., Sarmento, B., Ferreira, D. C., and Souto, E. B. (2007). Lipid-based colloidal carriers for peptide and protein delivery - liposomes versus lipid nanoparticles. Int. J. Nanomed. 2, 595-607.

Mathew, A., Fukuda, T., Nagaoka, Y., Hasumura, T., Morimoto, H., Yoshida, Y., et al. (2012). Curcumin loaded-plga nanoparticles conjugated with tet-1 peptide for potential use in alzheimer's disease. PLoS One 7:e32616. doi: 10. 1371/journal.pone.0032616

Matsumura, Y., Hamaguchi, T., Ura, T., Muro, K., Yamada, Y., Shimada, Y., et al., (2004). Phase I clinical trial and pharmacokinetic evaluation of NK911, a micelle-encapsulated doxorubicin. Br. J. Cancer 91, 1775-1781. doi: 10.1038/ sj.bjc. 6602204

Mcintosh, D. P., Tan, X.-Y., Oh, P., and Schnitzer, J. E. (2002). Targeting endothelium and its dynamic caveolae for tissue-specific transcytosis in vivo: a pathway to overcome cell barriers to drug and gene delivery. Proc. Natl. Acad. Sci. U.S.A. 99, 1996-2001. doi: 10.1073/pnas.251662398

Mdzinarishvili, A., Sutariya, V., Talasila, P. K., Geldenhuys, W. J., and Sadana, P. (2013). Engineering triiodothyronine $(\mathrm{t} 3)$ nanoparticle for use in ischemic brain stroke. Drug Deliv. Transl. Res. 3, 309-317. doi: 10.1007/s13346-012-0117-118

Mellman, I. (1992). The importance of being acid: the role of acidification in intracellular membrane traffic. J. Exp. Biol. 172, 39-45.

Miele, D., Catenacci, L., Sorrenti, M., Rossi, S., Sandri, G., Malavasi, L., et al. (2019). Chitosan Oleate Coated Poly Lactic-Glycolic Acid (PLGA) nanoparticles versus chitosan oleate self-assembled polymeric micelles, loaded with resveratrol. Mar. Drugs 17:E515. doi: 10.3390/md17090515

Misra, A., Ganesh, S., Shahiwala, A., and Shah, S. P. (2003). Drug delivery to the central nervous system: a review. J. Pharm. Pharm. Sci. 6, 252-273.

Modi, G., Pillay, V., and Choonara, Y. E. (2010). Advances in the treatment of neurodegenerative disorders employing nanotechnology. Ann. N. Y. Acad. Sci. 1184, 154-172. doi: 10.1111/j.1749-6632.2009.05108x

Mohamed, F., and Van Der Walle, C. F. (2008). Engineering biodegradable polyester particles with specific drug targeting and drug release properties. J. Pharm. Sci. 97, 71-87. doi: 10.1002/jps.21082

Mohanraj, K., Sethuraman, S., and Krishnan, U. M. (2013). Development of poly (butylene succinate) microspheres for delivery of levodopa in the treatment of parkinson's disease. J. Biomed. Mater. Res. B Appl. Biomater. 101, 840-847. doi: $10.1002 / j b m . b .32888$

Morgen, M., Bloom, C., Beyerinck, R., Bello, A., Song, W., Wilkinson, K., et al., (2012). Polymeric nanoparticles for increased oral bioavailability and rapid absorption using celecoxib as a model of a low-solubility, highpermeability drug. Pharm. Res. 29, 427-440. doi: 10.1007/s11095-011-05 $58-557$
Mourtas, S., Lazar, A. N., Markoutsa, E., Duyckaerts, C., and Antimisiaris, S. G. (2014). Multifunctional nanoliposomes with curcumin-lipid derivative and brain targeting functionality with potential applications for alzheimer disease. Eur. J Med. Chem. 80, 175-183. doi: 10.1016/j.ejmech.2014.04.050

Mukherjee, S., Ray, S., and Thakur, R. (2009). Solid lipid nanoparticles: a modern formulation approach in drug delivery system. Ind. J. Pharm. Sci. 71, 349. doi: 10.4103/0250-474X.57282

Mulik, R. S., MöNkköNen, J., Juvonen, R. O., Mahadik, K. R., and Paradkar, A. R. (2010). Apoe3 mediated poly (butyl) cyanoacrylate nanoparticles containing curcumin: study of enhanced activity of curcumin against beta amyloid induced cytotoxicity using in vitro cell culture model. Mol. Pharm. 7, 815-825. doi: $10.1021 / \mathrm{mp} 900306 \mathrm{x}$

Musacchio, T., and Torchilin, V. P. (2011). Recent developments in lipid-based pharmaceutical nanocarriers. Front. Biosci. 16:412. doi: 10.2741/3795

Nagpal, K., Singh, S. K., and Mishra, D. N. (2013). Drug targeting to brain: a systematic approach to study the factors, parameters and approaches for prediction of permeability of drugs across BBB. Expert Opin. Drug Deliv. 10, 927-955. doi: 10.1517/17425247.2013.762354

Naksuriya, O., Okonogi, S., Schiffelers, R. M., and Hennink, W. E. (2014). Curcumin nanoformulations: a review of pharmaceutical properties and preclinical studies and clinical data related to cancer treatment. Biomaterials 35, 3365-3383. doi: 10.1016/j.biomaterials.2013.12.090

Nisi Zhang, F. Y., Liang, X., Wu, M., Shen, Y., Chen, M., Xu, Y., et al. (2018). Localized delivery of curcumin into brain with polysorbate 80-modified cerasomes by ultrasound-targeted microbubble destruction for improved parkinson's disease therapy. Theranostics 8:2264. doi: 10.7150/thno.23734

Nunes, A., Al-Jamal, K. T., and Kostarelos, K. (2012). Therapeutics, imaging and toxicity of nanomaterials in the central nervous system. J. Control Rel. 161, 290-306. doi: 10.1016/j.jconrel.2012.03.026

Ojha, S., and Kumar, B. (2018). A review on nanotechnology based innovations in diagnosis and treatment of multiple sclerosis. J. Cell Immunother. 4, 56-64. doi: 10.1016/j.jocit.2017.12.001

Onoue, S., Aoki, Y., Kawabata, Y., Matsui, T., Yamamoto, K., Sato, H., et al. (2011a). Development of inhalable nanocrystalline solid dispersion of tranilast for airway inflammatory diseases. J. Pharm. Sci. 100, 622-633. doi: 10.1002/jps. 22299

Onoue, S., Kuriyama, K., Uchida, A., Mizumoto, T., and Yamada, S. (2011b). Inhalable sustained-release formulation of glucagon: in vitro amyloidogenic and inhalation properties, and in vivo absorption and bioactivity. Pharm. Res. 28, 1157-1166. doi: 10.1007/s11095-011-0379-8

Onoue, S., Nakamura, T., Uchida, A., Ogawa, K., Yuminoki, K., Hashimoto, N., et al. (2013). Physicochemical and biopharmaceutical characterization of amorphous solid dispersion of nobiletin, a citrus polymethoxylated flavone, with improved hepatoprotective effects. Eur. J. Pharm. Sci. 49, 453-460. doi: 10.1016/j.ejps.2013.05.014

Onoue, S., Takahashi, H., Kawabata, Y., Seto, Y., Hatanaka, J., Timmermann, B., et al. (2010). Formulation design and photochemical studies on nanocrystal solid dispersion of curcumin with improved oral bioavailability. J. Pharm. Sci. 99, 1871-1881. doi: 10.1002/jps.21964

Onoue, S., Uchida, A., Kuriyama, K., Nakamura, T., Seto, Y., Kato, M., et al. (2012). Novel solid self-emulsifying drug delivery system of coenzyme Q10 with improved photochemical and pharmacokinetic behaviors. Eur. J. Pharm. Sci. 46, 492-499. doi: 10.1016/j.ejps.2012.03.015

Onoue, S., Yamada, S., and Chan, H. K. (2014). Nanodrugs: pharmacokinetics and safety. Int. J. Nanomed. 9, 1025-1037. doi: 10.2147/IJN. S38378

Özdemir, Y. G., Pehlivan, S. B., and Sekerdag, E. (2017). Nanotechnology Methods for Neurological Diseases and Brain Tumors: Drug Delivery Across the BloodBrain Barrier. Cambridge, MA: Academic Press.

Ozkizilcik, A., Davidson, P., Turgut, H., Sharma, H. S., Sharma, A., and Tian, Z. R. (2017). "Nanocarriers as cns drug delivery systems for enhanced neuroprotection," in Drug and Gene Delivery to the Central Nervous System for Neuroprotection, eds H. S. Sharma, D. F. Muresanu, and A. Sharma (Berlin: Springer), 33-55.

Pai, A. S., Rubinstein, I., and Önyüksel, H. (2006). Pegylated phospholipid nanomicelles interact with $\beta$-amyloid (1-42) and mitigate its $\beta$-sheet formation, aggregation and neurotoxicity in vitro. Peptides 27, 2858-2866. doi: 10.1016/j. peptides.2006.04.022 
Palmal, S., Maity, A. R., Singh, B. K., Basu, S., Jana, N. R., and Jana, N. R. (2014). Inhibition of amyloid fibril growth and dissolution of amyloid fibrils by curcumin-gold nanoparticles. Chemistry 20, 6184-6191. doi: 10.1002/chem. 201400079

Pandey, R., Ahmad, Z., Sharma, S., and Khuller, G. K. (2005). Nano-encapsulation of azole antifungals: potential applications to improve oral drug delivery. Int. J. Pharm. 301, 268-276. doi: 10.1016/j.ijpharm.2005.05.027

Pardridge, W. M. (1999). Vector-mediated drug delivery to the brain. Adv. Drug Deliv. Rev. 36, 299-321. doi: 10.1016/s0169-409x(98)00087-88

Pardridge, W. M. (2007). Shrna and sirna delivery to the brain. Adv. Drug Deliv. Rev. 59, 141-152. doi: 10.1016/j.addr.2007.03.008

Pardridge, W. M. (2012). Drug transport across the blood-brain barrier. J. Cereb. Blood Flow Metab. 32, 1959-1972. doi: 10.1038/jcbfm.2012. 126

Parikh, A., Kathawala, K., Tan, C. C., Garg, S., and Zhou, X.-F. (2017). Lipidbased nanosystem of edaravone: development, optimization, characterization and in vitro/in vivo evaluation. Drug Deliv. 24, 962-978. doi: 10.1080/10717544. 2017

Park, J. H., Lee, S., Kim, J.-H., Park, K., Kim, K., and Kwon, I. C. (2008). Polymeric nanomedicine for cancer therapy. Prog. Polym.Sci. 33, 113-137.

Parton, R. G., and Simons, K. (2007). The multiple faces of caveolae. Nat. Rev. Mol. Cell Biol. 8, 185-194. doi: 10.1038/nrm2122

Pathak, P., and Nagarsenker, M. (2009). Formulation and evaluation of lidocaine lipid nanosystems for dermal delivery. AAPS Pharm. Sci. Tech. 10, 985-992. doi: 10.1208/s12249-009-9287-9281

Pathan, S. A., Iqbal, Z., Zaidi, S. M., Talegaonkar, S., Vohra, D., Jain, G. K., et al. (2009). Cns drug delivery systems: novel approaches. Recent Pat. Drug Deliv. Formul. 3, 71-89. doi: 10.2174/187221109787158355

Paviolo, C., Haycock, J. W., Yong, J., Yu, A., Stoddart, P. R., and Mcarthur, S. L. (2013). Laser exposure of gold nanorods can increase neuronal cell outgrowth. Biotechnol. Bioeng. 110, 2277-2291. doi: 10.1002/bit.24889

Peng, T., Britton, G. L., Kim, H., Cattano, D., Aronowski, J., Grotta, J., et al. (2013). Therapeutic time window and dose dependence of xenon delivered via echogenic liposomes for neuroprotection in stroke. CNS Neurosci. Ther. 19, 773-784. doi: $10.1111 /$ cns.12159

Pepic, I., Jalsenjak, N., and Jalsenjak, I. (2004). Micellar solutions of triblock copolymer surfactants with pilocarpine. Int. J. Pharm. 272, 57-64. doi: 10.1016/ j.ijpharm.2003.11.032

Piao, H., Kamiya, N., Hirata, A., Fujii, T., and Goto, M. (2008). A novel solid-in-oil nanosuspension for transdermal delivery of diclofenac sodium. Pharm. Res. 25, 896-901. doi: 10.1007/s11095-007-9445-9447

Podolski, I. Y., Podlubnaya, Z., Kosenko, E., Mugantseva, E., Makarova, E., Marsagishvili, L., et al. (2007). Effects of hydrated forms of c60 fullerene on amyloid $\beta$-peptide fibrillization in vitro and performance of the cognitive task. J. Nanosci. Nanotechnol. 7, 1479-1485. doi: 10.1166/jnn.2007.330

Poovaiah, N., Davoudi, Z., Peng, H., Schlichtmann, B., Mallapragada, S., Narasimhan, B., et al. (2018). Treatment of neurodegenerative disorders through the blood-brain barrier using nanocarriers. Nanoscale 10, 16962 16983. doi: 10.1039/c8nr04073g

Prajapati, R. N., Tekade, R. K., Gupta, U., Gajbhiye, V., and Jain, N. K. (2009). Dendimermediated solubilization, formulation development and in vitroin vivo assessment of piroxicam. Mol. Pharm. 6, 940-950. doi: 10.1021/ mp8002489

Pucadyil, T. J., and Schmid, S. L. (2009). Conserved functions of membrane active gtpases in coated vesicle formation. Science 325, 1217-1220. doi: 10.1126/ science. 1171004

Rajadhyaksha, M., Boyden, T., Liras, J., El-Kattan, A., and Brodfuehrer, J. (2011). Current advances in delivery of biotherapeutics across the blood-brain barrier. Curr. Drug Discov. Technol. 8, 87-101. doi: 10.2174/157016311795563866

Ramos-Cabrer, P., and Campos, F. (2013). Liposomes and nanotechnology in drug development: focus on neurological targets. Int. J Nanomed. 8:951. doi: 10.2147/IJN.S30721

Rappoport, J. Z. (2008). Focusing on clathrin-mediated endocytosis. Biochem. J. 412, 415-423. doi: 10.1042/BJ20080474

Ray, B., Bisht, S., Maitra, A., Maitra, A., and Lahiri, D. K. (2011). Neuroprotective and neurorescue effects of a novel polymeric nanoparticle formulation of curcumin (nanocurc) in the neuronal cell culture and animal model: implications for alzheimer's disease. J. Alzheimer Dis. 23, 61-77. doi: 10.3233/ JAD-2010-101374

Reddy, J. S., and Venkateswarlu, V. (2004). Novel delivery systems for drug targeting to the brain. Drugs Future 29, 63-83.

Reddy, L. H., Sharma, R. K., Chuttani, K., Mishra, A. K., and Murthy, R. R. (2004). Etoposideincorporated tripalmitin nanoparticles with different surface charge: formulation, characterization, radiolabeling, and biodistribution studies. AAPS J. 6:e23. doi: 10.1208/aapsj060323

Riggio, C., Calatayud, M. P., Giannaccini, M., Sanz, B., Torres, T. E., FernándezPacheco, R., et al. (2014). The orientation of the neuronal growth process can be directed via magnetic nanoparticles under an applied magnetic field. Nanomed. Nanotechnol. 10, 1549-1558. doi: 10.1016/j.nano.2013.12.008

Riggio, C., Calatayud, M. P., Hoskins, C., Pinkernelle, J., Sanz, B., Torres, T. E., et al. (2012). Poly-l-lysine-coated magnetic nanoparticles as intracellular actuators for neural guidance. Int. J Nanomed. 7:3155. doi: 10.2147/IJN.S28460

Sacco, R. L., Kasner, S. E., Broderick, J. P., Caplan, L. R., Connors, J., Culebras, A., et al. (2013). An updated definition of stroke for the 21 st century: a statement for healthcare professionals from the american heart association/american stroke association. Stroke 44, 2064-2089. doi: 10.1161/STR.0b013e318296aeca

Sadekar, S., Thiagarajan, G., Bartlett, K., Hubbard, D., Ray, A., Mcgill, L., et al. (2013). Poly (amido amine) dendrimers as absorption enhancers for oral delivery of camptothecin. Int. J. Pharm. 456, 175-185. doi: 10.1016/j.ijpharm. 2013.07.07

Sahoo, S. K., Misra, R., and Parveen, S. (2017). Nanoparticles: a boon to drug delivery, therapeutics, diagnostics and imaging. Nanomedicine 8, 73-124. doi: 10.1016/j.nano.2011.05.016

Sainz, V., Conniot, J., Matos, A. I., Peres, C., Zupancic, E., Moura, L., et al. (2015) Regulatory aspects on nanomedicines. Biochem. Biophys. Res. Commun. 468, 504-510. doi: 10.1016/j.bbrc.2015.08.023

Samia, O., Hanan, R., and Kamal, E. T. (2012). Carbamazepine mucoadhesive nanoemulgel (mneg) as brain targeting delivery system via the olfactory mucosa. Drug Deliv. 19, 58-67. doi: 10.3109/10717544.2011. 644349

Sanai, N., and Berger, M. S. (2008). Glioma extent of resection and its impact on patient outcome. Neurosurgery 62, 753-766. doi: 10.1227/01.neu.0000318159. 21731.cf

Sandhir, R., Yadav, A., Mehrotra, A., Sunkaria, A., Singh, A., and Sharma, S. (2014). Curcumin nanoparticles attenuate neurochemical and neurobehavioral deficits in experimental model of huntington's disease. Neuromol. Med. 16, 106-118. doi: 10.1007/s12017-013-8261-y

Sarker, D. K. (2005). Engineering of nanoemulsions for drug delivery. Curr. Drug Deliv. 2, 297-310. doi: 10.2174/156720105774370267

Sarmah, D., Saraf, J., Kaur, H., Pravalika, K., Tekade, R., Borah, A., et al. (2017). Stroke management: an emerging role of nanotechnology. Micromachines 8:262. doi: $10.3390 / \mathrm{mi} 8090262$

Schmidt, J., Metselaar, J. M., Wauben, M. H., Toyka, K. V., Storm, G., and Gold, R. (2003). Drug targeting by long-circulating liposomal glucocorticosteroids increases therapeutic efficacy in a model of multiple sclerosis. Brain 126, 1895-1904. doi: 10.1093/brain/awg176

Schubert, D., Dargusch, R., Raitano, J., and Chan, S. W. (2006). Cerium and yttrium oxide nanoparticles are neuroprotective. Biochem. Biophys. Res. Commun. 342, 86-91. doi: 10.1016/j.bbrc.2006.01.129

Shah, L., Yadav, S., and Amiji, M. (2013). Nanotechnology for cns delivery of biotherapeutic agents. Drug Deliv. Transl. Res. 3, 336-351. doi: 10.1007/s13346013-0133-133

Sharma, A., Sharma, S., and Khuller, G. K. (2004). Lectin-functionalized poly (lactide-co-glycolide) nanoparticles as oral/aerosolized antitubercular drug carriers for treatment of tuberculosis. J. Antimicrob. Chemother. 54, 761-766. doi: 10.1093/jac/dkh411

Sharma, H. S., and Sharma, A. (2007). Nanoparticles aggravate heat stress induced cognitive deficits, blood-brain barrier disruption, edema formation and brain pathology. Prog. Brain Res. 162, 245-273. doi: 10.1016/S0079-6123(06) 62013-X

Sharma, R., Kim, S.-Y., Sharma, A., Zhang, Z., Kambhampati, S. K., Kannan, S., et al. (2017). Activated microglia targeting dendrimer-minocycline conjugate as therapeutics for neuroinflammation. Bioconjugate Chem. 28, 2874-2886. doi: 10.1021/acs.bioconjchem.7b00569 
Shegokar, R., and Müller, R. H. (2010). Nanocrystals: industrially feasible multifunctional formulation technology for poorly soluble actives. Int. J. Pharm. 399, 129-139. doi: 10.1016/j.ijpharm.2010.07.044

Silva, G. A. (2005). Nanotechnology approaches for the regeneration and neuroprotection of the central nervous system. Surg. Neurol. 63, 301-306. doi: 10.1016/j.surneu.2004.06.008

Silva, G. A. (2008). Nanotechnology approaches to crossing the blood-brain barrier and drug delivery to the cns. BMC Neurosci. 9:S4. doi: 10.1186/1471-2202-9-S3S4

Singh, A. V., Khare, M., Gade, W., and Zamboni, P. (2012). Theranostic implications of nanotechnology in multiple sclerosis: a future perspective. Autoimmune Dis. 2012:160830. doi: 10.1155/2012/160830

Sloane, P. D., Zimmerman, S., Suchindran, C., Reed, P., Wang, L., Boustani, M., et al. (2002). The public health impact of alzheimer's disease, 20002050: potential implication of treatment advances. Annu. Rev. Publ. Health 23, 213-231. doi: 10.1146/annurev.publhealth.23.100901.140525

Soni, V., Kohli, D., and Jain, S. (2008). Transferrin-conjugated liposomal system for improved delivery of 5-fluorouracil to brain. J. Drug Target 16, 73-78. doi: 10.1080/10611860701725381

Soursou, G., Alexiou, A., Md Ashraf, G., Ali Siyal, A., Mushtaq, G., and Kamal, M. A. (2015). Applications of nanotechnology in diagnostics and therapeutics of alzheimer's and parkinson's disease. Curr. Drug Metab. 16, 705-712. doi: $10.2174 / 138920021608151107125049$

Strickley, R. G. (2004). Solubilizing excipients in oral and injectable formulations. Pharm. Res. 21, 201-230. doi: 10.1023/b:pham.0000016235.32639.23

Sun, C., Wang, J., Liu, J., Qiu, L., Zhang, W., and Zhang, L. (2013). Liquid proliposomes of nimodipine drug delivery system: preparation, characterization, and pharmacokinetics. AAAPS Pharm. Sci. Tech. 14, 332-338. doi: 10.1208/s12249-013-9924-9926

Sylvestre, J. P., Tang, M. C., Furtos, A., Leclair, G., Meunier, M., and Leroux, J. C. (2011). Nanonization of megestrol acetate by laser fragmentation in aqueous milieu. J. Control Rel. 149, 273-280. doi: 10.1016/j.jconrel.2010.10.034

Tajes, M., Ramos-Fernández, E., Weng-Jiang, X., Bosch-Morató, M., Guivernau, B., Eraso-Pichot, A., et al. (2014). The blood-brain barrier: structure, function and therapeutic approaches to cross it. Mol. Membr. Biol. 31, 152-167. doi: 10.3109/09687688.2014.937468

Takamiya, M., Miyamoto, Y., Yamashita, T., Deguchi, K., Ohta, Y., and Abe, K. (2012). Strong neuroprotection with a novel platinum nanoparticle against ischemic stroke-and tissue plasminogen activator-related brain damages in mice. Neuroscience 221, 47-55. doi: 10.1016/j.neuroscience.2012. 06.060

Taylor, M., Moore, S., Mourtas, S., Niarakis, A., Re, F., Zona, C., et al. (2011). Effect of curcumin-associated and lipid ligand-functionalized nanoliposomes on aggregation of the alzheimer's a $\beta$ peptide. Nanomed. Nanotechnol. 7, 541550. doi: 10.1016/j.nano.2011.06.015

Teshima, M., Fumoto, S., Nishida, K., Nakamura, J., Ohyama, K., Nakamura, T., et al. (2006). Prolonged blood concentration of prednisolone after intravenous injection of liposomal palmitoyl prednisolone. J. Control Rel. 112, 320-328. doi: 10.1016/j.jconrel.2006.03.004

Thomas, N., Holm, R., Garmer, M., Karlsson, J. J., Müllertz, A., and Rades, T. (2013). Supersaturated self-nanoemulsifying drug delivery systems (SuperSNEDDS) enhance the bioavailability of the poorly water-soluble drug simvastatin in dogs. AAPS J. 15, 219-227. doi: 10.1208/s12248-012-94339437

Thomas, N., Holm, R., Müllertz, A., and Rades, T. (2012). In vitro and in vivo performance of novel supersaturated self-nanoemulsifying drug delivery systems (super-SNEDDS). J. Control Rel. 160, 25-32. doi: 10.1016/j.jconrel. 2012.02.027

Tian, X.-H., Lin, X.-N., Wei, F., Feng, W., Huang, Z.-C., Wang, P., et al. (2011). Enhanced brain targeting of temozolomide in polysorbate-80 coated polybutylcyanoacrylate nanoparticles. Int. J. Nanomed. 6:445. doi: 10.2147/IJN. S16570

Tiwari, S. B., and Amiji, M. M. (2006). Improved oral delivery of paclitaxel following administration in nanoemulsion formulations. J. Nanosci. Nanotechnol. 6, 3215-3221. doi: 10.1166/jnn.2006.440

Tiwari, S. K., Agarwal, S., Seth, B., Yadav, A., Nair, S., Bhatnagar, P., et al. (2013). Curcumin-loaded nanoparticles potently induce adult neurogenesis and reverse cognitive deficits in alzheimer's disease model via canonical wnt/ $\beta$-catenin pathway. ACS Nano 8, 76-103. doi: 10.1021/nn40 $5077 y$

Tomalia, D. A. (2005). Birth of a new macromolecular architecture: dendrimers as quantized building blocks for nanoscale synthetic polymer chemistry. Prog. Polym. Sci. 30, 294-324. doi: 10.1016/j.progpolymsci.2005. 01.007

Tomii, Y. (2002). Lipid formulation as a drug carrier for drug delivery. Curr. Pharm. Des. 8, 467-474. doi: 10.2174/138161202339587.1

Torchilin, V. P. (2007). Micellar nanocarriers: pharmaceutical perspectives. Pharm. Res. 24:1. doi: 10.1007/s11095-006-9132-9130

Tripathy, S., and Das, M. K. (2013). Dendrimers and their applications as novel drug delivery carriers. J. Appl. Pharm. Sci. 3, 142-149. doi: 10.7324/JAPS.2013. 3924

Vega-Villa, K. R., Takemoto, J. K., Yáñez, J. A., Remsberg, C. M., Forrest, M. L., and Davies, N. M. (2008). Clinical toxicities of nanocarrier systems. Adv. Drug Deliv Rev. 60, 929-938. doi: 10.1016/j.addr.2007.11.007

Ventola, C. L. (2017). Progress in nanomedicine: approved and investigational nanodrugs. $P$ T 42, 742-755.

Vilella, A., Tosi, G., Grabrucker, A. M., Ruozi, B., Belletti, D., Vandelli. M. A., et al. (2014). Insight on the fate of CNS-targeted nanoparticles. Part I: Rab5dependent cell-specific uptake and distribution. J. Control Rel. 174, 195-201. doi: 10.1016/j.jconrel.2014.01.004

Vinogradov, S. V., Batrakova, E. V., and Kabanov, A. V. (2004). Nanogels for oligonucleotide delivery to the brain. Bioconjugate Chem. 15, 50-60. doi: 10. $1021 /$ bc034164r

Wang, Y., Cooke, M. J., Sachewsky, N., Morshead, C. M., and Shoichet, M. S. (2013). Bioengineered sequential growth factor delivery stimulates brain tissue regeneration after stroke. J. Control Rel. 172, 1-11. doi: 10.1016/j.jconrel.2013. 07.032

Watanabe, M., Kawano, K., Yokoyama, M., Opanasopit, P., Okano, T., and Maitani, Y. (2006). Preparation of camptothecin-loaded polymeric micelles, and evaluation of their incorporation, and circulation stability. Int. J. Pharm. 308, 183-189. doi: 10.1016/j.ijpharm.2005.10.030

Wilson, B., Samanta, M. K., Santhi, K., Kumar, K. P. S., Paramakrishnan, N., and Suresh, B. (2008). Poly (n-butylcyanoacrylate) nanoparticles coated with polysorbate 80 for the targeted delivery of rivastigmine into the brain to treat alzheimer's disease. Brain Res. 1200, 159-168. doi: 10.1016/j.brainres.2008.01. 039

Witt, J., and Marks, W. J. (2011). An update on gene therapy in parkinson's disease. Curr. Neurol. Neurosci. Rep. 11, 362-370. doi: 10.1007/s11910-011-0197-8

Wohlfart, S., Gelperina, S., and Kreuter, J. (2012). Transport of drugs across the blood-brain barrier by nanoparticles. J. Control Rel. 161, 264-273. doi: 10.1016/ j.jconrel.2011.08.017

Wong, H. L., Bendayan, R., Rauth, A. M., Li, Y., and Wu, X. Y. (2007). Chemotherapy with anticancer drugs encapsulated in solid lipid nanoparticles. Adv. Drug deliv. Rev. 59, 491-504. doi: 10.1016/j.addr.2007.04.008

Wong, H. L., Wu, X. Y., and Bendayan, R. (2012). Nanotechnological advances for the delivery of cns therapeutics. Adv. Drug Deliv. Rev. 64, 686-700. doi: 10.1016/j.addr.2011.10.007

Wu, C. Y., and Benet, L. Z. (2005). Predicting drug disposition via application of BCS: transport/absorption/elimination interplay and development of a biopharmaceutics drug disposition classification system. Pharm. Res. 22, 11-23. doi: 10.1007/s11095-004-9004-4

Xia, D., Cui, F., Piao, H., Cun, D., Piao, H., Jiang, Y., et al. (2010). Effect of crystal size on the in vitro dissolution and oral absorption of nitrendipine in rats. Pharm. Res. 27, 1965-1976. doi: 10.1007/s11095-0100200-0

Xing, C., Levchenko, T., Guo, S., Stins, M., Torchilin, V. P., and Lo, E. H. (2012). Delivering minocycline into brain endothelial cells with liposome-based technology. J. Cereb. Blood Flow Metab. 32, 983-988. doi: 10.1038/jcbfm.2012.48

$\mathrm{Xu}, \mathrm{L}$. , Zhang, H., and Wu, Y. (2013). Dendrimer advances for the central nervous system delivery of therapeutics. ACS Chem. Neurosci. 5, 2-13.

$\mathrm{Xu}, \mathrm{L}$., Zhang, H., and Wu, Y. (2014). Dendrimer advances for the central nervous system delivery of therapeutics. ACS Chem. Neurosci. 5, 2-13. doi: 10.1021/ cn $400182 \mathrm{z}$

Yang, F., Lim, G. P., Begum, A. N., Ubeda, O. J., Simmons, M. R., Ambegaokar, S. S., et al. (2005). Curcumin inhibits formation of amyloid $\beta$ oligomers and fibrils, 
binds plaques, and reduces amyloid in vivo. J. Biol. Chem. 280, 5892-5901. doi: 10.1074/jbc.M404751200

Yang, Z., Zhang, Y., Yang, Y., Sun, L., Han, D., Li, H., et al. (2010). Pharmacological and toxicological target organelles and safe use of single-walled carbon nanotubes as drug carriers in treating alzheimer disease. Nanomedicine 6, 427-441. doi: 10.1016/j.nano.2009.11.007

Ye, C., Pan, B., Xu, H., Zhao, Z., Shen, J., Lu, J., et al. (2019). Co-delivery of GOLPH3 siRNA and gefitinib by cationic lipid-PLGA nanoparticles improves EGFR-targeted therapy for glioma. J. Mol. Med. 11, 1575-1588. doi: 10.1007/ s00109-019-01843-1844

Yemisci, M., Caban, S., Gursoy-Ozdemir, Y., Lule, S., Novoa-Carballal, R., Riguera, R., et al. (2015). Systemically administered brain-targeted nanoparticles transport peptides across the blood-brain barrier and provide neuroprotection. J. Cereb. Blood Flow Metab. 35, 469-475. doi: 10.1038/jcbfm. 2014.220

Yusuf, M., Khan, R. A., Khan, M., and Ahmed, B. (2012). Plausible antioxidant biomechanics and anticonvulsant pharmacological activity of brain-targeted $\beta$-carotene nanoparticles. Int. J. Nanomed. 7:4311. doi: 10.2147/IJN.S34588

Zeis, T., Probst, A., Steck, A. J., Stadelmann, C., Brück, W., and SchaerenWiemers, N. (2009). Molecular changes in white matter adjacent to an active demyelinating lesion in early multiple sclerosis. Brain Pathol. 19, 459-466. doi: 10.1111/j.1750-3639.2008.00231.x

Zhang, L., Gu, F. X., Chan, J. M., Wang, A. Z., Langer, R. S., and Farokhzad, O. C. (2008). Nanoparticles in medicine: therapeutic applications, and developments. Clin. Pharmacol. Ther. 83, 761-769. doi: 10.1038/sj.clpt.61 00400

Zhang, N., Ping, Q., Huang, G., Xu, W., Cheng, Y., and Han, X. (2006). Lectinmodified solid lipid nanoparticles as carriers for oral administration of insulin. Int. J. Pharm. 327, 153-159. doi: 10.1016/j.ijpharm.2006.07.026

Zhang, P., Hu, L., Yin, Q., Feng, L., and Li, Y. (2012). Transferrin-modified c[rgdfk]-paclitaxel loaded hybrid micelle for sequential blood-brain barrier penetration and glioma targeting therapy. Mol. Pharm. 9, 1590-1598. doi: 10. $1021 / \mathrm{mp} 200600 \mathrm{t}$
Zhang, Y., Calon, F., Zhu, C., Boado, R. J., and Pardridge, W. M. (2003). Intravenous nonviral gene therapy causes normalization of striatal tyrosine hydroxylase and reversal of motor impairment in experimental parkinsonism. Hum. Gene Ther. 14, 1-12. doi: 10.1089/10430340360464660

Zhao, H., Bao, X.-J., Wang, R.-Z., Li, G.-L., Gao, J., Ma, S.-H., et al. (2010). Postacute ischemia vascular endothelial growth factor transfer by transferrintargeted liposomes attenuates ischemic brain injury after experimental stroke in rats. Hum. Gene Ther. 22, 207-215. doi: 10.1089/hum.2010.111

Zhu, S., Hong, M., Tang, G., Qian, L., Lin, J., Jiang, Y., et al. (2010a). Partly pegylated polyamidoamine dendrimer for tumor-selective targeting of doxorubicin: the effects of pegylation degree and drug conjugation style. Biomaterials 31, 13601371. doi: 10.1016/j.biomaterials.2009.10.044

Zhu, S., Hong, M., Zhang, L., Tang, G., Jiang, Y., and Pei, Y. (2010b). Pegylated pamam dendrimer-doxorubicin conjugates: in vitro evaluation and in vivo tumor accumulation. Pharm. Res. 27, 161-174. doi: 10.1007/s11095-010-0217-4

Zong, T., Mei, L., Gao, H., Cai, W., Zhu, P., Shi, K., et al. (2014). Synergistic dualligand doxorubicin liposomes improve targeting and therapeutic efficacy of brain glioma in animals. Mol. Pharm. 11, 2346-2357. doi: 10.1021/mp500057n

Zou, Z., Jiang, X., Zhang, W., Zhou, Y., Ke, Y., Zhang, S., et al. (2010). Efficacy of tyrosine hydroxylase gene modified neural stem cells derived from bone marrow on parkinson's disease-a rat model study. Brain Res. 1346, 279-286. doi: 10.1016/j.brainres.2010.05.071

Conflict of Interest: The authors declare that the research was conducted in the absence of any commercial or financial relationships that could be construed as a potential conflict of interest.

Copyright (c) 2020 Naqvi, Panghal and Flora. This is an open-access article distributed under the terms of the Creative Commons Attribution License (CC BY). The use, distribution or reproduction in other forums is permitted, provided the original author(s) and the copyright owner(s) are credited and that the original publication in this journal is cited, in accordance with accepted academic practice. No use, distribution or reproduction is permitted which does not comply with these terms. 